\title{
Shape-memory behavior of cross-linked semi-crystalline polymers and their blends
}

\author{
I. Kolesov, O. Dolynchuk, H.-J. Radusch* \\ Martin Luther University Halle-Wittenberg, Center of Engineering Sciences, D-06099 Halle, Germany
}

Received 30 September 2014; accepted in revised form 29 November 2014

\begin{abstract}
The present study deals with thermally induced one-way and invertible two-way shape-memory effect (SME) in covalent networks on the basis of crystallizable (co)polymers and their blends and is an attempt to generalize the results of own investigation received by the authors in the last ten years. The main focus of work clearly lies on research of covalently crosslinked binary and ternary blends having two and three crystalline phases with different thermal stability, respectively. The existence of two or three crystalline phases possessing different melting and crystallization temperatures in heterogeneous polymer networks can lead to triple-shape or even quadruple-shape behavior of such networks. However, the performed investigations point to crucial effect of phase morphology of crosslinked polymer blends on multiplicity of their shapememory behavior beside the influence of blend content, crystallinity and cross-link density of blend phases as well as of processing conditions. For instance, triple-shape memory behavior in binary blends can be realized only if the continuous phase has a lower melting temperature than the dispersed phase. Cross-linked polymer blends are a facile alternative to expensive and complex synthesis of interpenetrating or block-copolymer networks used for shape memory polymers. In addition to findings of experimental investigation of SME in crystallizable covalent polymer networks, the results of modeling their shape-memory behavior on the basis of self-developed physically reasonable model have been briefly described and discussed. Thereby, good accordance between results of theory and experiment was achieved with physically justified fitting parameters.
\end{abstract}

Keywords: smart polymers, shape-memory effect, polymer blends, crystallizable polymer networks, cross-linking

\section{Introduction}

The aim of present mini-review is an attempt to perform the comparative description and analysis of results of our experimental investigation and of physically justified modeling of unconstrained one-way shape-memory effect (SME) and invertible twoway SME under load in crystallizable covalent polymer networks. Besides the dual SME in cross-linked homopolymers, the one- and two-way multi-shape behavior in heterogeneous networks on the basis of binary and ternary blends will be discussed. The special focus in present work is directed on the key role of phase morphology of cross-linked polymer blends varied by blend composition on the performances of multiple SM behavior.

\subsection{Brief overview of various types of SME in polymeric materials}

In the last decades the SME in polymeric materials was the research object of hundreds of original papers and many reviews (see for instance [1-8]). There are four main types of stimuli, which are able to trigger a shape change of polymeric materials: temperature variation, chemical reactions, light, and mechanical forces [2-7]. Correspondingly, among polymeric materials the thermo-, chemo-, photo-, and mechano-responsive material groups can be classified. In majority of publications, which consider SM behavior of polymer systems, the subject of investigation are thermo-responsive polymeric materials. According to the existence of ordered

\footnotetext{
*Corresponding author, e-mail: hans-joachim.radusch@iw.uni-halle.de (C) BME-PT
} 
nano-structure, the availability of thermal transitions in relevant temperature ranges, and of stable netpoints or entanglements within thermo-responsive polymeric materials, they can be divided into following pairs - amorphous and crystallizable polymer systems, polymer systems in which glass transition or melting/crystallization is responsible for switching mechanism, as well as covalent and physical polymer networks, respectively. Our research activities in the field of SM polymeric materials are focused on uniform and heterogeneous covalent networks on the basis of crystallizable polymers, because such crystallizable polymer networks besides irreversible one-way SME enable to create also invertible two-way SME in contrast to amorphous physical polymer networks where glass transition is used as switching mechanism.

\subsection{One-way SME in polymeric materials}

One-way SME arises predominantly from thermal triggering of recovery of pre-deformed SM polymeric material occurred at a temperature in the range of such a thermal phenomenon as melting or glass transition, i.e. being a thermally induced SME. The remarkable appearance of thermally induced oneway SME is realizable for polymeric materials, which possess either a stable covalent or a physical network (entanglements or block-copolymer domains) and reveal at least one of mentioned thermal transitions. The initial (permanent) shape can be transferred to the temporary shape by means of deformation (e.g. stretching) of specimen at temperature above melting or glass transition temperature depending on SM polymer type.

Formation of crystalline structure or vitrification during the subsequent cooling under constant load fixes this temporary shape so well, that it remains nearly unchanged also after unloading of a sample at low (room) temperature. The entropy-elastic and viscoelastic forces originating from deformation in rubber-elastic state are stored inside the temporary shaped sample during its cooling to temperature below crystallization or glass transition point. Described procedure is referred to as programming

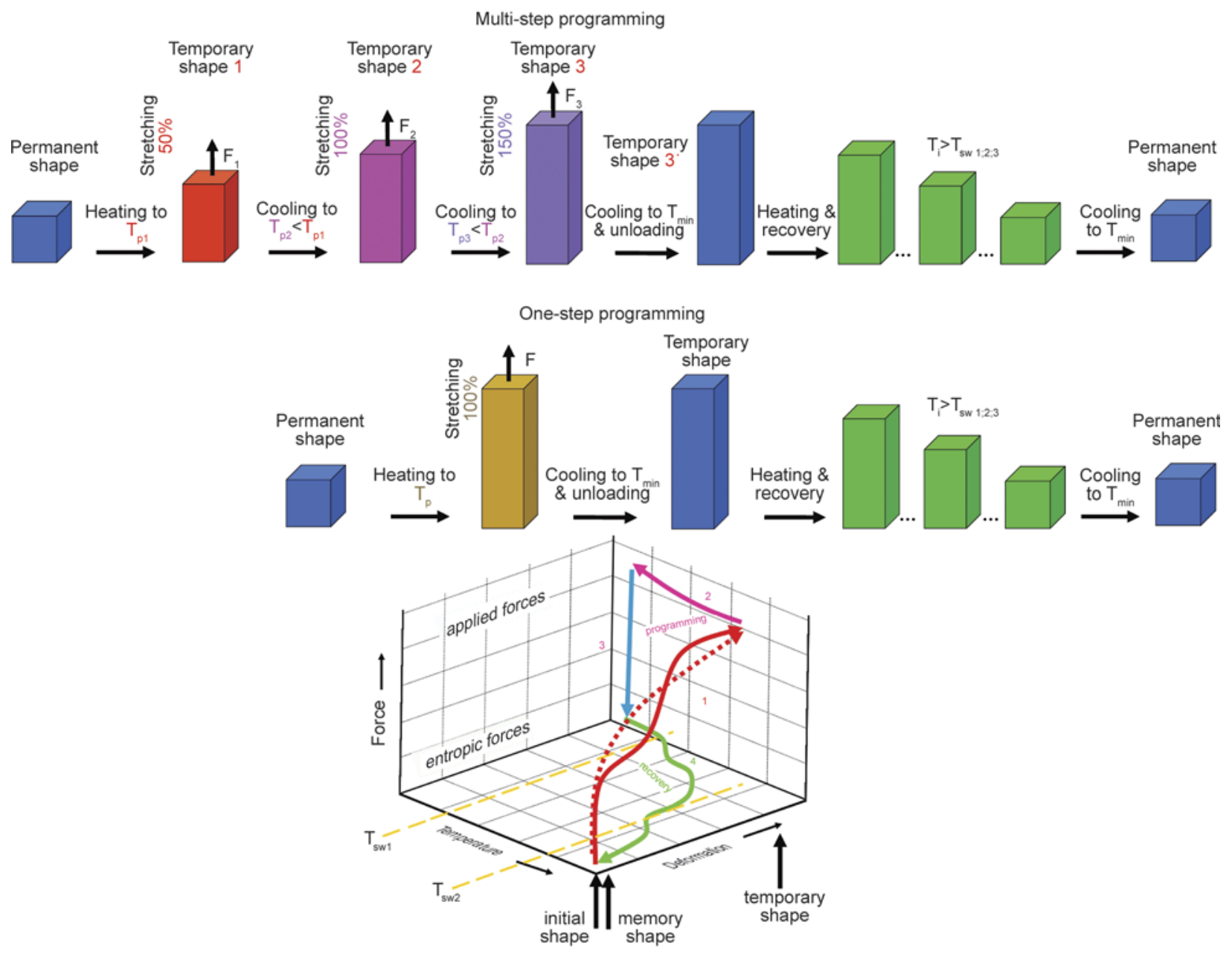

Figure 1. General shape memory behavior of thermally triggered polymer material 
and is necessary for observation of one-way SME. Programming can be performed either at constant strain or at constant loading force. Programmed samples can be stored below their crystallization and melting temperatures $\left(T_{\mathrm{c}}\right.$ and $\left.T_{\mathrm{m}}\right)$, which are usually higher than room temperature [1-6].

At heating of programmed samples the stored entropic and viscoelastic forces serve as the driving force of recovery of temporary shape back to permanent (initial) shape, whereas the melting or glass transition fulfills the function of triggering or switching mechanism [1-6] as shown schematically in Figure 1.

Polymer networks possessing several crystalline phases with different crystallization/melting temperatures enable to observe not only singular but also multiple SM behavior. Multiple switchable SM polymer materials, which evince triple-shape behavior, have been developed some time ago as presented by Bellin et al. [9]. The main disadvantage of such SM polymers is a need for the application of special multi-step programming (MSP) process in order to produce the appearance of more or less considerable SM recovery steps during heating at two or more different temperatures [9]. Later it was demonstrated by Behl et al. [10] that complex multiphase $\mathrm{AB}$ copolymer networks created on the basis of poly (E-caprolactone) and poly(cyclohexyl methacrylate) with suitable compositions show a pronounced tripleshape behavior with good SM characteristics after simple one-step programming (OSP) process.

Disadvantages of MSP compared to OSP process are technical complexity, diffuse indistinct steps and peaks of SM recovery strain and rate, respectively, as well as relatively low values of strain fixing $\left(R_{\mathrm{f}}\right)$ and strain recovery $\left(R_{\mathrm{r}}\right)$ ratios. This undesirable effect during MSP has to be expected as a consequence of the drastic increase of irreversible deformation part caused by plastic deformation of already crystallized phase in the second and third programming steps. Polymer materials, which reveal multiple SME, are highly innovative smart materials, which permit a number of novel engineering, medical, and pharmaceutical applications $[9,10]$. Because of great importance of aforementioned applications, SM polymer materials with relatively low switching temperatures $\left(T_{\mathrm{sw}}\right)$, which are nearly equal to melting temperatures of their crystalline phases, are a matter of particular interest.
As an alternative to an expensive synthesis of complex interpenetrating networks and copolymers the multiple SM effects can be also achieved in covalent networks on the basis of polymer blends, if suitable phase morphology can be generated [11-13]. The distinct occurrence of triple-shape effect in polymer composites on the basis of electrospun PCL fibers embedded in an epoxy-based copolymer thermoset system was reported by Luo and Mather [11]. The temperature dependence of SM recovery strain obtained for this system both after two-step programming as well as after one-step programming (OSP) exhibit two well observable steps/decrements in temperature ranges of glass transition of epoxymatrix and of PCL melting.

For blends of linear and short-chain branched polyethylenes cross-linked by peroxide an appreciable multiple SM behavior with relatively low characteristics could be achieved only by MSP process [12]. It is assumed that this is caused by the high affinity of blend components in molten state and correspondingly by insufficiently segregated crystalline phases of different thermal stability, also indicated by results of DSC investigations [12]. Also, heterogeneous blends of polyethylenes (PEs) and thermodynamically incompatible trans-polyoctenamer (TOR) with suitable compositions cross-linked via high energy electrons (HEE) show pronounced triple-shape behavior with high performance and even weakly pronounced quadruple-shape behavior after simple OSP process [13].

Similarly, the pronounced triple-shape behavior in bending mode was described independently from us in the same year by Cuevas et al. [14] in blend of TOR and linear medium polyethylene $(20 \mathrm{wt} \% \mathrm{TOR} /$ $20 \mathrm{wt} \% \mathrm{PE}$ ) cross-linked by $1-3 \mathrm{wt} \%$ dicumyl peroxide.

Note that initially the binary uncross-linked meltmiscible $[2,8]$ and melt-immiscible polymer blends [15] were used in order to obtain SM polymeric materials with relatively stable physical network. In these blends the crystalline domains with higher thermal stability play a role of physical cross-links, whereas the domains of amorphous or less stable crystalline phase serve as switching segments. The blends of poly(vinyl acetate) (PVAc) with poly(lactic acid) (PLA) and PVAc or PMMA with poly (vinylidene fluoride) (PVDF) are indicative of meltmiscible polymer blends $[2,8]$. Blends of maleated 
PE with nylon/polyamide 6 as disperse phase can be cited as an example of melt-immiscible polymer blends [15].

Shape-memory effects depicted by Xie [16] as multiple SM effects cannot be considered as a true multiple SM behavior because of the use of special temperature program consisted of temperature soak (isothermal) segments in addition to temperature ramps during SM recovery measurements. Number and location of these isothermal segments and steps in SM recovery curves show an explicit correlation, which points to the kinetic nature of mentioned steps. The similar drawbacks are contained in some recently published papers [17, 18]. One-way 'triple'-shape behavior of crystallizable covalent networks on the basis of PE/polypropylene (PP) blends with co-continuous phase morphology and on the basis of PCL grafted by $0.5-2.0 \mathrm{wt} \%$ of polydopamin (PDA) was evaluated as 'pronounced' and 'good', respectively, using temperature dependencies of SM recovery of these networks after their two-step programming $[17,18]$. However, this interpretation cannot be accepted because the used temperature-time program contained the isothermal segment between two temperature ramps just within temperature range where the first step of SM recovery strain arises. Because of the application of SMPs in medicine and pharmacology as intended e.g. by Lendlein and coworkers [3, 4, 19] and Mather and coworkers [2, 6] the biodegradable polyester-based shape-memory polymers have been a matter of particular interest [20]. On the other hand, as mentioned by KargerKocsis and coworkers [20,21], potential applications for SMP exist in nearly every area of daily life: from self-repairing car bodies to kitchen utensils, from switches to sensors, from intelligent packing to tools.

\subsection{Two-way SME in polymeric materials}

The main focus of our investigation has been directed to the creation of two-way SM polymers on the basis of crystallizable covalently cross-linked polymers and their blends. Invertible thermally induced twoway SME in tensile mode can be initiated only in crystallizable covalent polymer networks loaded by suitable constant force. This two-way SME can be observed for preloaded strips of polymer networks in repeating thermal cycles 'cooling-heating'. At cooling of initially stretched strip the oriented crystallization of network leads to an anomalous elongation (creep) of specimen. The subsequent melting of crystalline phase triggers the shrinkage of specimen, which results in mechanical work carried out against an external force.

The recent findings have shown that cross-linked semi-crystalline polymers also possess an invertible so-called two-way SME that has been observed for covalent networks on the basis of polycyclooctene/ trans-polyoctenamer $(\mathrm{PCO} / \mathrm{TOR})$ and of $\operatorname{poly}(\varepsilon-$ caprolactone) (PCL) [22-24]. The physical background of two-way SME is on the one hand the anomalous elongation of a sample, which is initiated by the non-isothermal crystallization during cooling under load (at a constant force) and accompanied by an increase of storage modulus, and on the other hand the expected contraction of a sample during heating under the same load triggered by melting of the oriented crystalline phase and by release of the entropic network forces. In contrast to irreversible one-way SME, invertible two-way SME can be reproduced repeatedly as long as a sample is loaded and temperature change is enough to cause consecutive crystallization and melting of the sample.

The performance of SME in cross-linked crystallizable polymers strongly depends on the properties of crystalline structure and of covalent polymer network, which has to be generated in the material. In the first instance, these are $T_{\mathrm{m}}$ value and crystallinity as a function of the temperature, which are dependent on crystal size and perfection, as well as crosslink density and related mechanical properties of the network, such as storage modulus, strain at break, and unrecoverable residual strain $[25,26]$.

Recently, the two-way SME with marked triple-shape behavior under suitable load was demonstrated for polymer networks based on crystallizable segments of poly ( $\omega$-pentadecalactone) and poly( $\varepsilon$-caprolactone) by Zotzmann et al. [27]. Both crystallization and melting of specified segment types occur at two different temperatures and are responsible for two increments and two decrements of strain at corresponding temperatures.

The two-way SME in PCL-PDA graft polymer network was reported by Bai et al. [18]. However, these networks demonstrated only negligible values of increment and decrement of SM creep and recovery strain, respectively, which amount merely few percents (3-4\%) in spite of relatively large load of 1.32.0 $\mathrm{MPa}$ [18]. Therefore the practical application of these polymer networks as actuators or sensors should be hardly realizable. 
Some current papers [28-33] containing results on two-way SME of layered polymer composites consider two other types of thermally induced two-way SME based on quite different physical principles as described above. So, the thermally induced reversible bending of active asymmetric layered polymer composites-laminates reported by Basit et al. [28] and Imai [29] occurs similarly to the well-known bimetallic strip effect in unconstrained as well as constrained state and under load [28, 29]. Westbrook et al. [30] described the reversible deformation of free-standing cross-linked polymer system in bending mode, while Behl and coworkers $[31,32]$ as well as $\mathrm{Wu}$ et al. [33] reported on reversible deformation of freestanding cross-linked polymer systems in tensile mode caused by internal stresses stored at least in one semi-crystalline phase of the polymer system during its preparation.

\subsection{Modeling of one- and two-way SME in polymeric materials}

The rapid development and discovery of novel manifestations of SM behavior in polymeric materials require precise and adequate physically grounded modeling of SM phenomena. However, a small number of scientific publications deals with theoretical description of SME, [34-45] especially in crosslinked semi-crystalline polymers [35, 36, 43, 46]. Majority of authors consider predominantly amorphous SM polymers with the glass transition as a switching mechanism and entangled macromolecules as a network [34, 37-42, 44, 45]. Only several scientific groups have tried their theoretical modeling of one-way SM behavior for cross-linked semicrystalline polymers in case of the deformation about $100 \%$ and more $[43,46]$. Nevertheless, some circumstances, like insufficient physical substantiation of used assumptions and meaningless of introduced fitting parameters, complicate description of SM recovery on the basis of these approaches. Note that only modeling based on the deep understanding of fundamental physical mechanisms and of main peculiar- ities of a material can serve as a reliable tool for the prediction and creation of SM polymers with predetermined properties. Furthermore, it should be emphasized that a simulation on the basis of welldefined model provides the fitting parameters having quite concrete physical meaning and giving new information about SME.

Up to now only one publication is known dealing with modeling of two-way SME in cross-linked semicrystalline polymers [46]. However, the authors used constitutive mechanical or engineering modeling and the most specific manifestation of two-way SME, the anomalous elongation under constant load during non-isothermal crystallization, was not physically explained as well as proposed assumptions remained unclear.

\section{Preparation of SM polymer networks}

All polymers used in our investigations are commercially available products. The blends have been prepared on the basis of polyethylenes from Dow Chemical (Germany) and predominantly of high-density polyethylene HDPE (KS 10100 UE), but partly also of metallocene-catalyzed homogeneous ethylene-octene copolymer (EOC) with approx. 30 or 60 hexyl branches per $1000 \mathrm{C}$ (AFFINITYTM), respectively. Poly( $\varepsilon$-caprolactone) (PCL) is biodegradable, high molecular weight linear polyester with trade name CAPA 6800 (Solvay, United Kingdom), which is derived from $\varepsilon$-caprolactone monomer via ring opening polymerization using catalyst. As another blend partner, which is thermodynamically incompatible with polyethylenes, polycyclooctene containing trans-polyoctenamer (TOR) with trade name VESTENAMER 8012 (Evonik Degussa, Germany) was employed. Few relevant parameters of these materials are given in Table 1.

The HDPE, PCL, EOC and binary HDPE/PCL and EOC/TOR blends containing cross-linking agent, namely 2,5-bis(t-butylperoxy)-2,5-dimethylhexane (DHBP) (Evonik, Germany) with different mass ratios of components (see Table 2) were prepared by

Table 1. Designations as well as some physical and molecular parameters of the used polymers

\begin{tabular}{|c|c|c|c|c|c|c|}
\hline \multirow[t]{2}{*}{ Designation } & \multirow{2}{*}{$\begin{array}{l}\mathbf{T}_{\mathbf{m}} \\
{\left[{ }^{\circ} \mathbf{C}\right]}\end{array}$} & \multirow{2}{*}{$\begin{array}{l}\text { Density } \\
{\left[\mathrm{kg} / \mathrm{m}^{3}\right]}\end{array}$} & \multicolumn{2}{|c|}{$\begin{array}{c}\text { Melt-Flow Index (MFI) } \\
\text { [dg/min] }\end{array}$} & \multirow{2}{*}{$\begin{array}{c}\text { Mass-average } \\
\text { molecular mass } \\
{[\mathrm{kg} / \mathrm{mol}]}\end{array}$} & \multirow{2}{*}{$\begin{array}{l}\text { Polydispersity } \\
\qquad \overline{\mathbf{M}}_{w} / \overline{\mathbf{M}}_{\mathbf{n}}\end{array}$} \\
\hline & & & $190^{\circ} \mathrm{C} / 2.16 \mathrm{~kg}$ & $190^{\circ} \mathrm{C} / 5.0 \mathrm{~kg}$ & & \\
\hline HDPE & 132 & 955 & 3.0 & 10.1 & $99 \pm 2$ & 4.3 \\
\hline EOC30/60 & $96 / 59$ & $900 / 870$ & $5.0 / 4.4$ & $17.7 / 15.9$ & $64 \pm 5 / 87 \pm 8$ & $2.3 / 2.5$ \\
\hline PCL & 61 & 1145 & 7.29 & - & $120 \pm 2$ & 1.74 \\
\hline TOR & 54 & 910 & 16.40 & 45.5 & $90 / 120$ & 7.3/9.7 \\
\hline
\end{tabular}


Table 2. Designations and compositions of semi-crystalline binary and ternary blends as well as their components

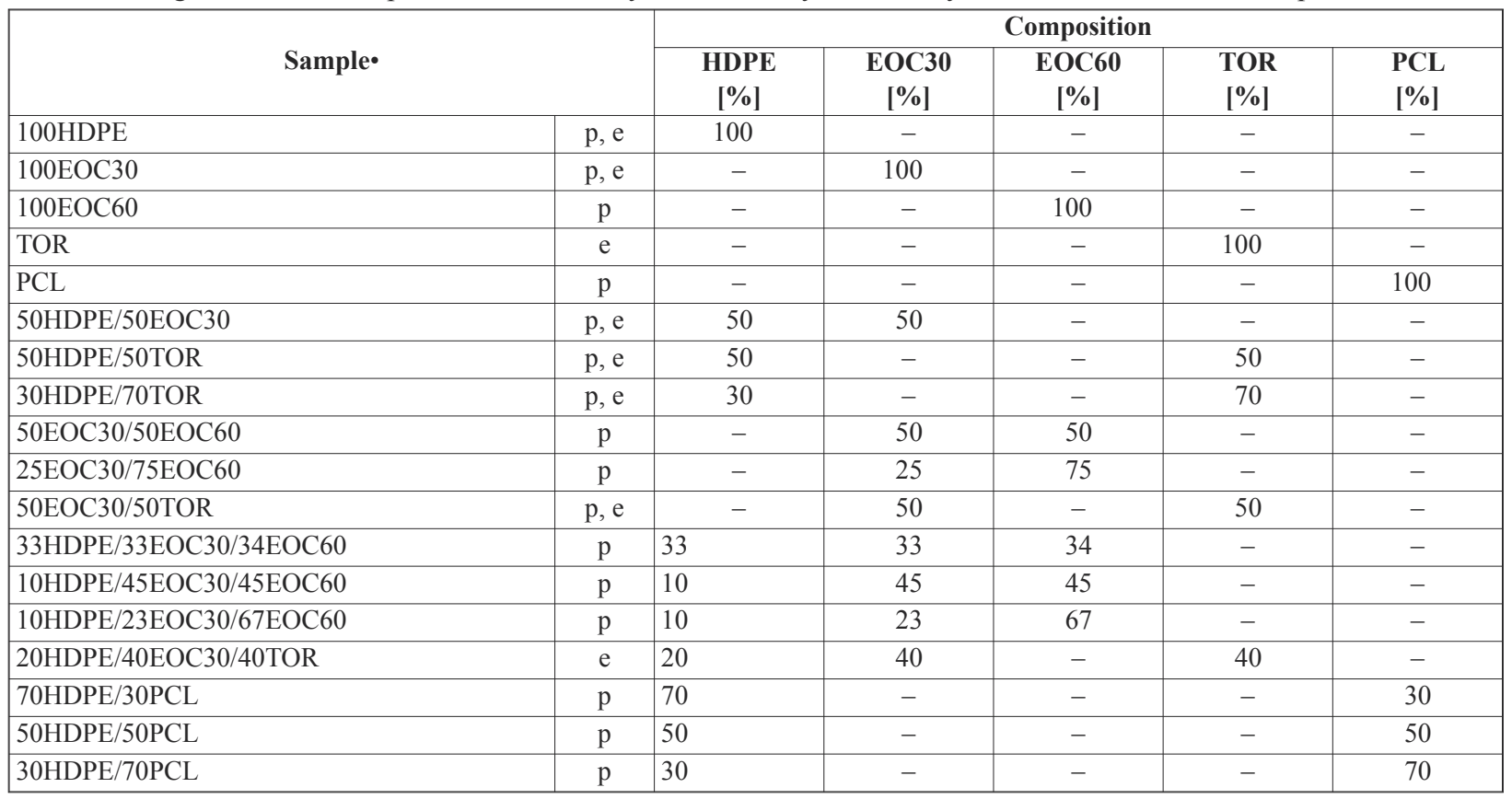

melt mixing in laboratory kneader (Brabender PlastiCorder) for $5 \mathrm{~min}$ at $140^{\circ} \mathrm{C}$. Films of TOR, EOC and HDPE as well as their blends with thickness of 0.5 and $1.0 \mathrm{~mm}$ were compression molded at $140^{\circ} \mathrm{C}$ and immediately afterwards cross-linked in press at $190^{\circ} \mathrm{C}$.

Binary HDPE/TOR and EOC30/TOR as well as ternary HDPE/EOC30/TOR blends and their components without cross-linking agent were prepared by melt mixing and compression molding under the same conditions. These samples were either slowly cooled $(s c)$ or quenched $(q)$ from the molten state and subsequently cross-linked via high energy electrons (HEE) with a radiation dose of $200 \mathrm{kGy}$ as described previously [13]. Such a preparation allows receiving two series of heterogeneous networks having different thermal history (TH) and correspondingly different phase morphology and crystalline properties.

Crosslink density of obtained covalent networks was evaluated on the basis of stress relaxation measurements performed during 3 hours at a constant temperature above melting temperature of all polymers under study. The crosslink density was calculated using Equation (1):

$\nu_{\mathrm{c}}=\frac{2 \cdot \sigma_{\infty}}{R T \cdot\left(\lambda-\lambda^{-2}\right)}$
Table 3. Crosslink density $\left(v_{\mathrm{c}}\right)$ of HDPE, PCL, EOC, TOR, as well as nominal $v_{\mathrm{c}}$ values of $50 \mathrm{EOC} / 50 \mathrm{TOR}$ and 30HDPE/70TOR blends

\begin{tabular}{|c|c|c|c|}
\hline \multirow[b]{2}{*}{ Sample } & \multicolumn{2}{|c|}{ Cross-linking method } & \multirow{2}{*}{$\begin{array}{c}\text { Crosslink } \\
\text { density, } \\
\mathbf{v}_{\mathrm{c}} \\
{\left[\mathrm{mol} / \mathrm{m}^{3}\right]}\end{array}$} \\
\hline & $\begin{array}{c}\text { Electron } \\
\text { irradiation dose } \\
{[\mathrm{kGy}]}\end{array}$ & $\begin{array}{l}\text { Peroxide } \\
\text { DHBP } \\
\text { [wt\%] }\end{array}$ & \\
\hline HDPE & - & 2.0 & 110 \\
\hline EOC30 & - & 2.0 & 270 \\
\hline \multirow{2}{*}{ PCL } & - & 1.3 & 139 \\
\hline & - & 2.0 & 252 \\
\hline 50EOC30/50TOR & - & 2.0 & 318 \\
\hline HDPE & 200 & - & 140 \\
\hline EOC30 & 200 & - & 148 \\
\hline TOR & 200 & - & 360 \\
\hline 30HDPE/70TOR & 200 & - & 260 \\
\hline
\end{tabular}

where $\sigma_{\infty}$ is terminal stress (stress at infinitely long time), $R$ is gas constant, $T$ is absolute temperature of sample, and $\lambda \approx 2$ is draw ratio.

The terminal stress $\sigma_{\infty}$ is obtained as fitting parameter as described previously [13, 26, 47]. The crosslink density values of cross-linked HDPE, EOC30, PCL and TOR as well as 30HDPE/70PCL and 30HDPE/70TOR blend are listed in Table 3.

\section{Phase morphology of heterogeneous SM polymer networks}

The strong correlation between phase morphology of the blends and multiple SM behavior was demon- 
strated by means of visualization of the phase morphology by scanning electron microscopy (SEM) investigation. The blends under study were etched in order to expose phase morphology. SEM images of 30HDPE/70TOR and 50EOC30/50TOR blends, which show very discrete melting and crystallization

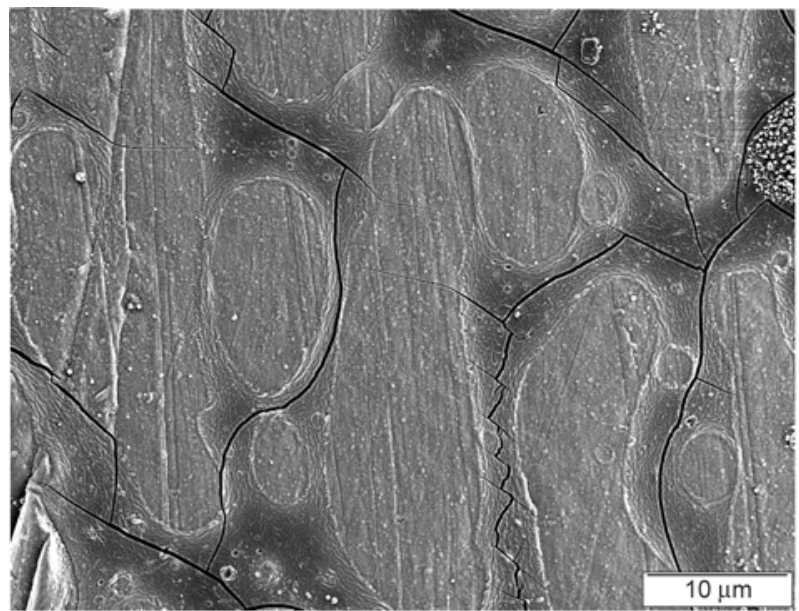

a)

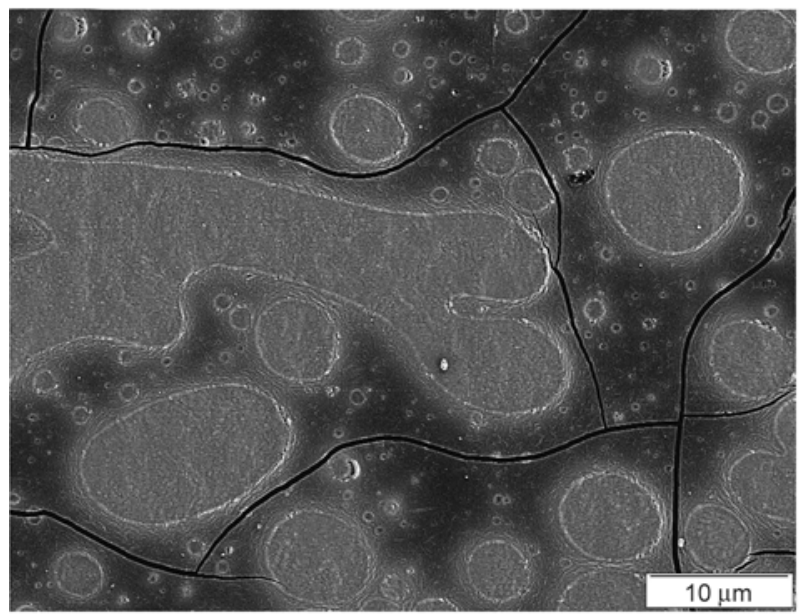

c)

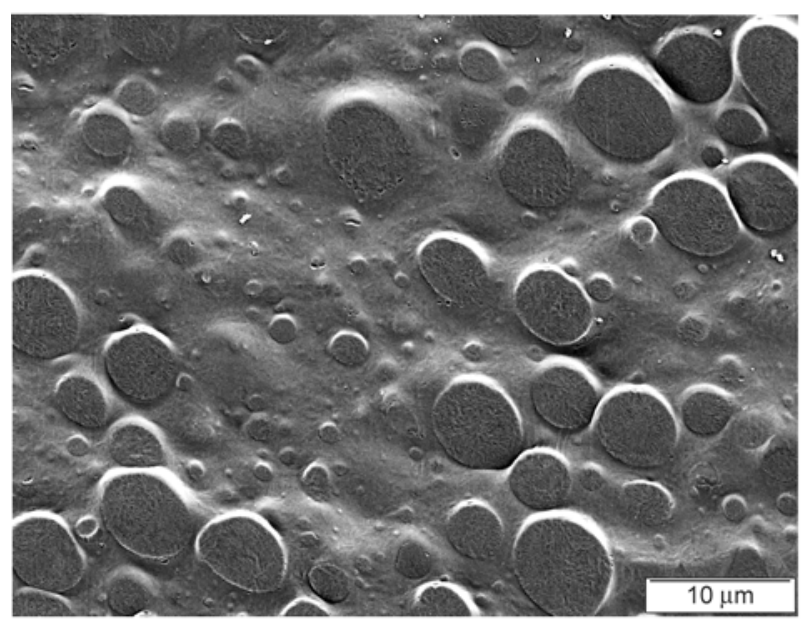

e) peaks for both components on DSC thermograms (see next section), reveal incompatibility between HDPE and TOR (Figure 2) as well as between EOC30 and TOR. Droplet-like or extended particles (Figure 2a-2c) with varying size from 1 to $50 \mu \mathrm{m}$, which are identified to be HDPE, indicate the dis-

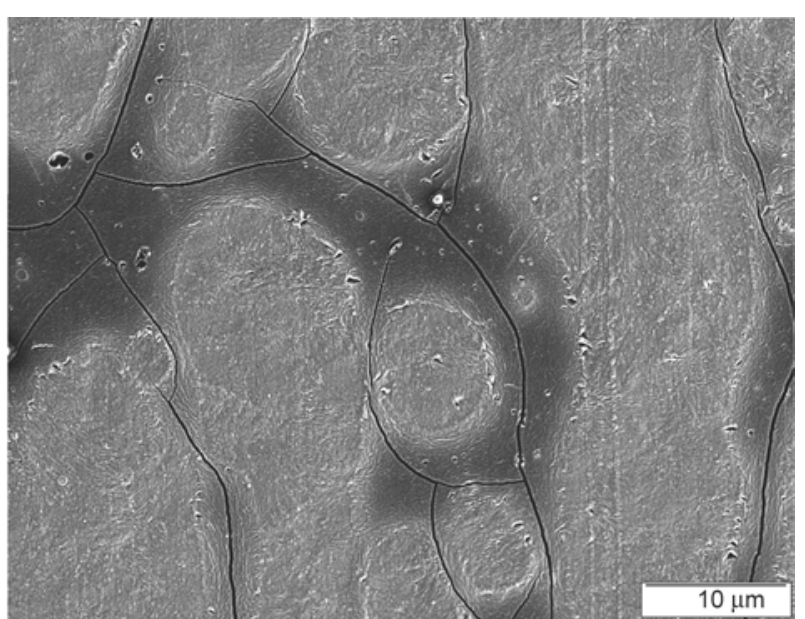

b)

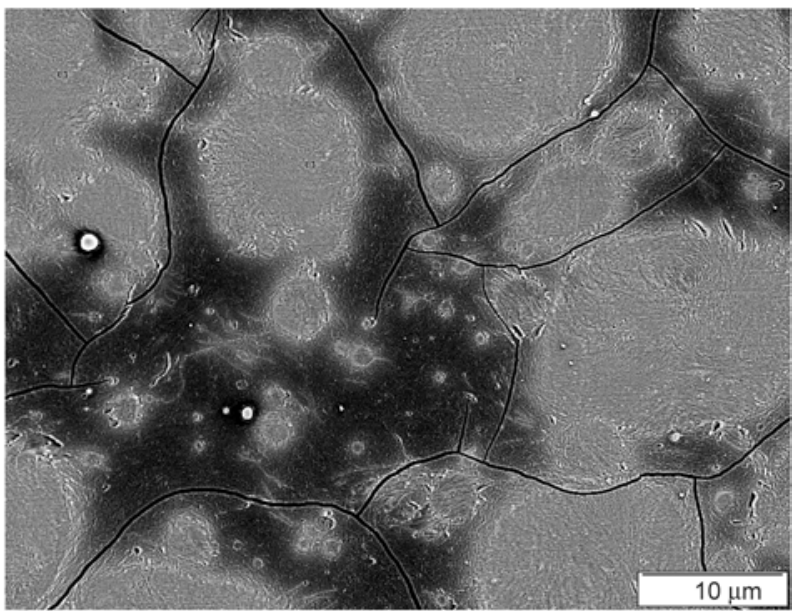

d)

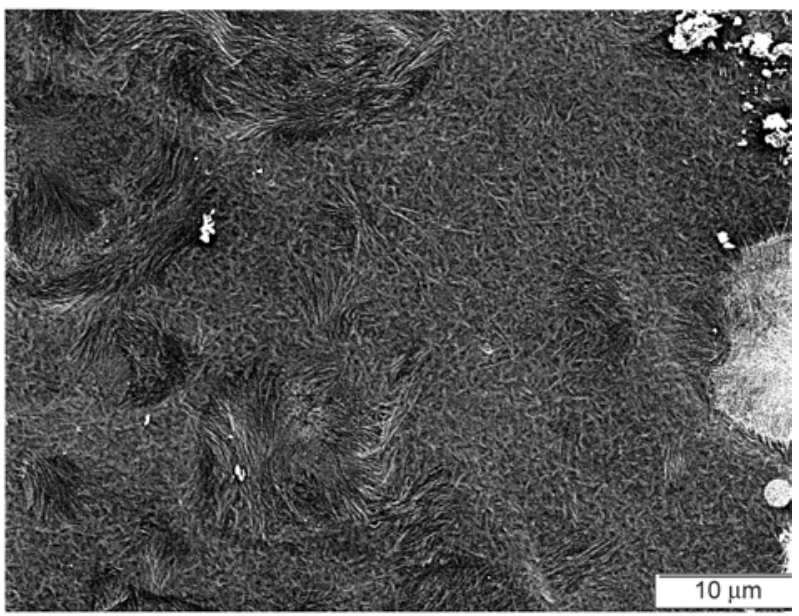

f)

Figure 2. SEM images of stained cryo sections of 50TOR/50HDPE (a, b) and 70TOR/30HDPE (c-f) blends, which were quenched ( $a, c$, and e) or slowly cooled (b, d, and f) from the melt before cross-linking. SEM images were obtained before $(\mathrm{a}-\mathrm{d})$ and after $(\mathrm{e}, \mathrm{f})$ removal of thin slices from surface of stained cryo sections [13]. 
persion of HDPE in TOR continuous phase, because the entire area of disperse phase of 50TOR/50HDPE blend is markedly larger in comparison to 70TOR/ 30HDPE blend.

It could be concluded that the HDPE disperse phase is segregated from the TOR continuous phase (matrix) as a result of their thermodynamic incompatibility.

In contrast, in the 50EOC30/50HDPE blend the separate phase was not able to be revealed by SEM. The SEM images of the 50EOC30/50HDPE blend with higher magnification (Figure $3 \mathrm{a}$ and $3 \mathrm{~b}$ ) demonstrate a poor supermolecular structure, which can be interpreted as distorted chaotically oriented lamellae caused by crystallization of both HDPE and EOC30. The SEM image of the 20HDPE/40EOC30/40TOR blend (Figure $3 \mathrm{c}$ and $3 \mathrm{~d}$ ) supports the assumption of thermodynamic incompatibility between TOR and EOC30/HDPE as there are only two contrasts for three components of blend in micrograph. The par-

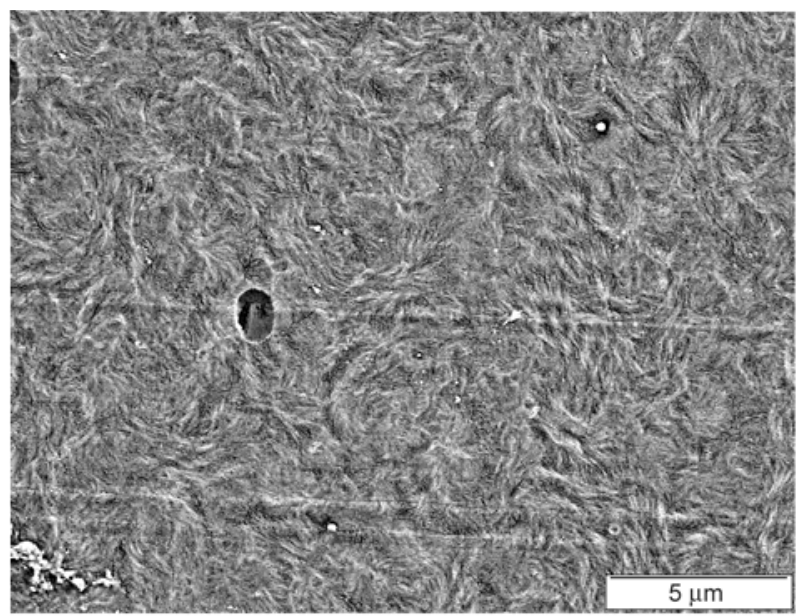

a)

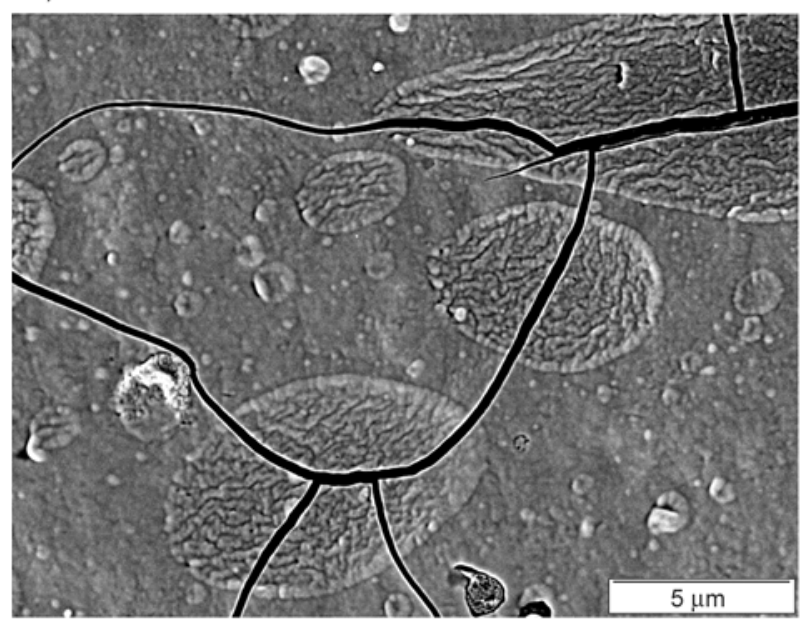

c) tial compatibility of HDPE and EOC is already pointed out in Figure $3 \mathrm{c}$ and $3 \mathrm{~d}$, therefore, HDPE and EOC30 are seen in the same contrast in the 20HDPE/40EOC30/40TOR micrograph.

Figure $2 \mathrm{e}$ and $2 \mathrm{f}$ as well as Figure $3 \mathrm{a}$ and $3 \mathrm{~b}$ illustrate that blends quenched before cross-linking ( $q$ preparation) show finer distribution of disperse phase and finer supermolecular structure of all phases in comparison to blends slowly cooled from the melt before cross-linking (sc preparation).

SEM images of cross-linked HDPE/PCL blends with three different proportions of components and the 50EOC30/50TOR blend are presented in Figure 4. Blends containing 70\% HDPE and 30\% PCL as well as 30\% HDPE and $70 \%$ PCL exhibit relatively raw but well segregated disperse phase of PCL and HDPE, respectively, in matrix of the second component as a result of their thermodynamic incompatibility. The size of particles of dispersed phase shows a bread distribution between approx. 2 and $10 \mu \mathrm{m}$.

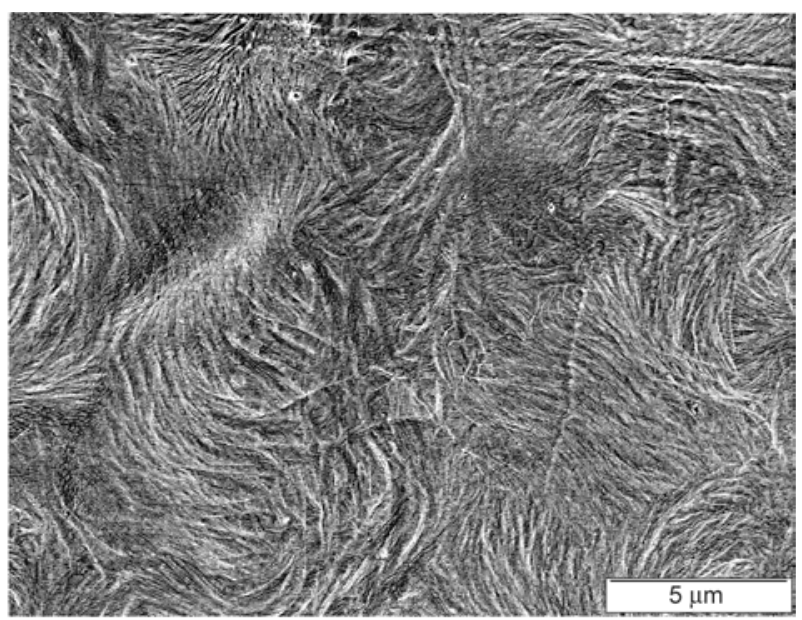

b)

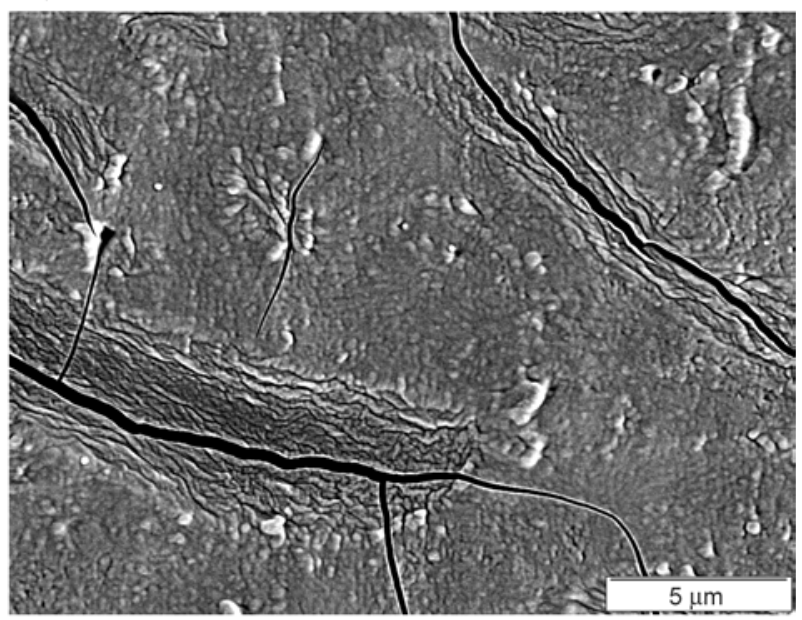

d)

Figure 3. SEM images of stained cryo sections of 50HDPE/50EOC30 (a, b) and 20HDPE/40EOC30/40TOR (c, d) blends quenched $(a, c)$ or slowly cooled $(b, d)$ from the melt before cross-linking. SEM images obtained before (c, d) and after $(a, b)$ removal of thin slices from surface of stained cryo sections [13]. 


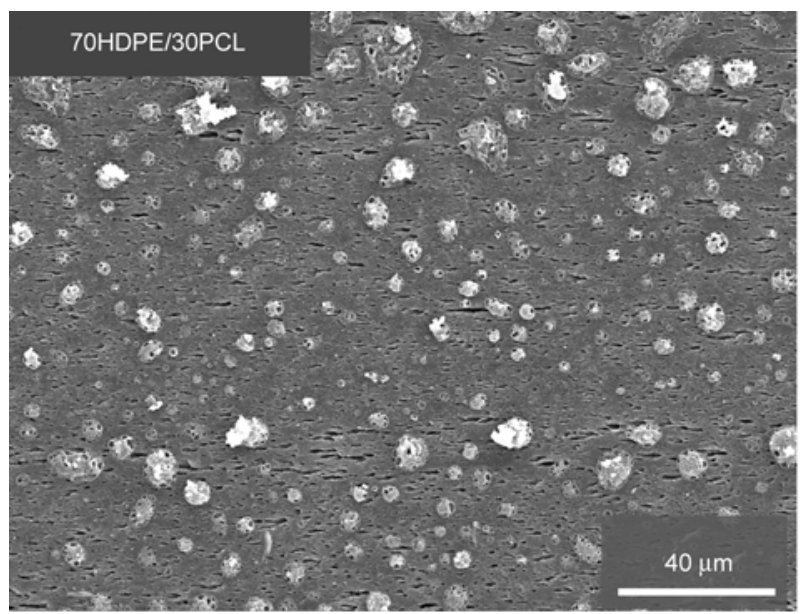

a)

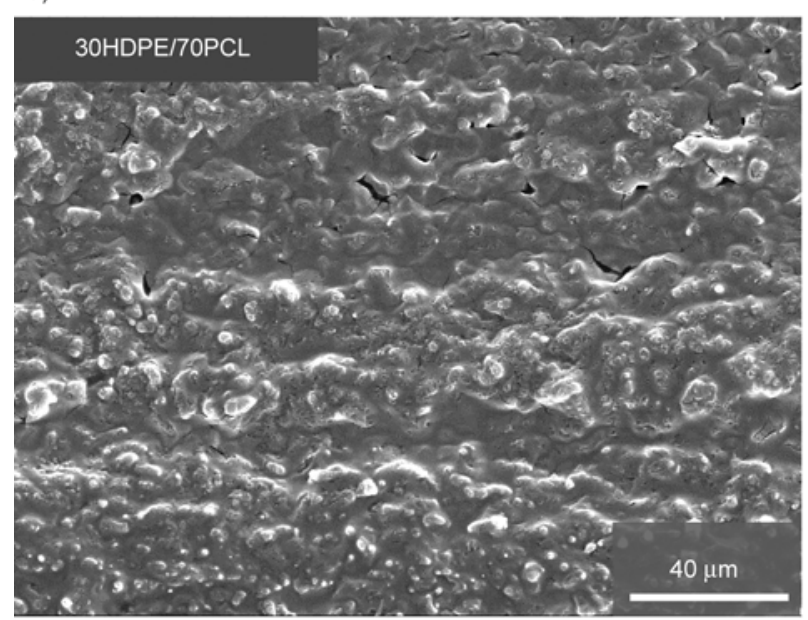

c)

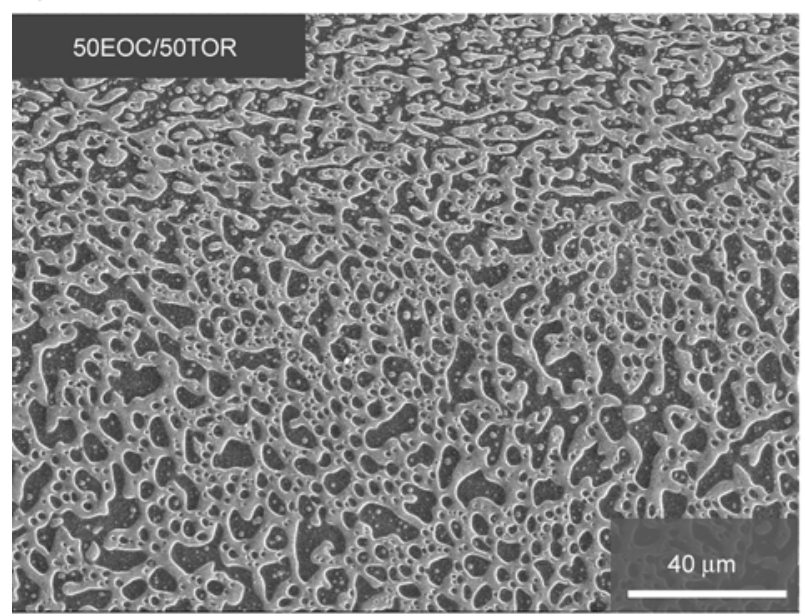

e)

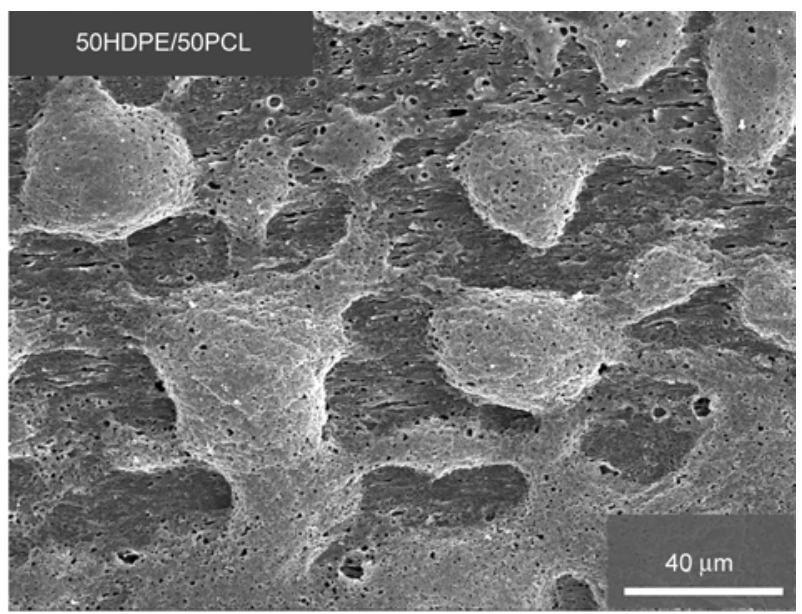

b)

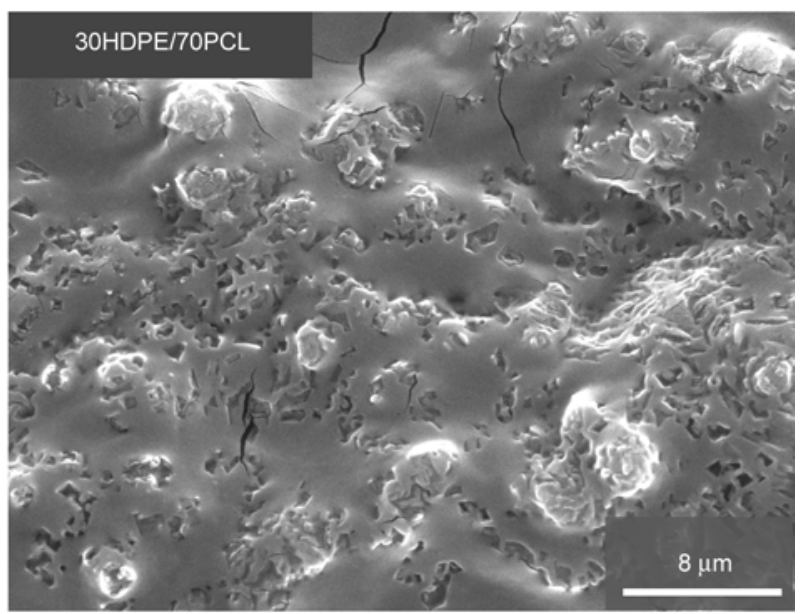

d)

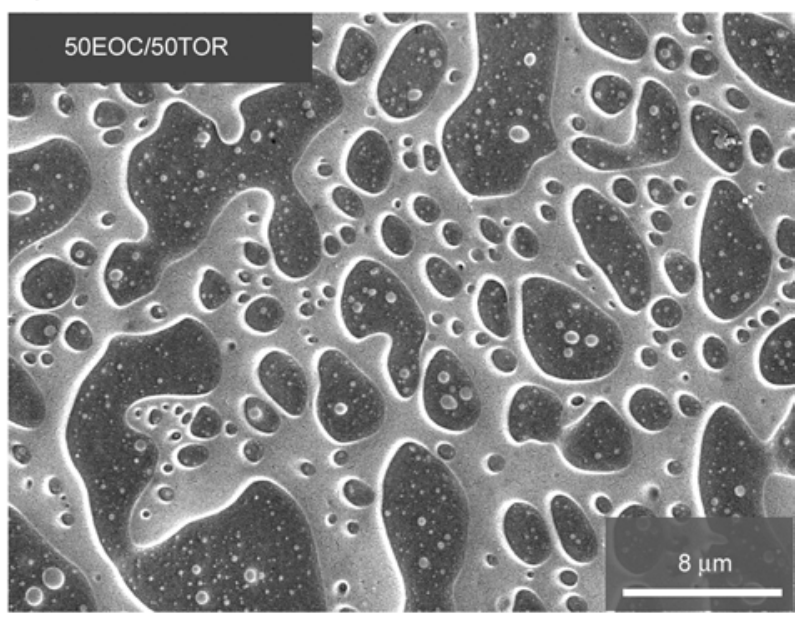

f)

Figure 4. SEM images of HDPE/PCL blends (a-d) cross-linked by $1.3 \mathrm{wt} \%$ DHBP and of 50EOC30/50TOR blend (e, f) cross-linked by $2.0 \mathrm{wt} \%$ DHBP [48]

The SEM image of the 50HDPE/50PCL blend (see image top/right) demonstrates pronounced tendency to a formation of co-continuous phase morphology. The melt-flow index (MFI) of TOR is roughly three times higher than MFI of used EOC30 (see Table 1). Therefore, in the 50EOC30/50TOR blend the TOR having markedly lower melt viscosity compared to
EOC30 forms a continuous phase with embedded coarse particles of disperse phase of EOC30. Interestingly, as proved by SEM images, the irregularshaped EOC30 particles in the size range between 2 and $15 \mu \mathrm{m}$ enclose nearly spherical fine-dispersed particles of TOR with diameter of about 0.3 to $1.5 \mu \mathrm{m}$. Thus, in 50EOC30/50TOR blend the simul- 
taneous coexistence of continuous and fine-dispersed TOR phases is available.

\section{Crystallization and melting behavior of heterogeneous SM polymer networks}

The pronounced phase segregation, which was demonstrated in previous section for the majority of investigated blends, results in multiple crystallization and melting behavior but leads not always to multiple SM behavior.

Melting and crystallization behavior of binary and ternary HDPE/EOC30/TOR blends, which were slowly cooled or quenched before HEE cross-linking are demonstrated in Figure 5. Melting peaks corresponding to components of both binary and ternary blends are slightly more discrete for slowly cooled $(s c)$ preparation than they are for samples quenched $(q)$ before HEE cross-linking. Note that $s c$ samples exhibit often peak splitting. Obviously, this is the result of phase separation depending on the thermal history before cross-linking and subsequent crystallization in crystallizable regions confined by cross-linking.

Melting and crystallization behavior of irradiated HDPE/EOC30/TOR blends, especially HDPE/TOR and EOC30/TOR binary blends, displays significantly discrete melting and crystallization peaks for all compositions (50HDPE/50TOR, 30HDPE/ 70TOR and 50EOC30/50TOR) in comparison to 50HDPE/50EOC30 blends. Discrete melting peaks point to a separation between crystalline TOR phase

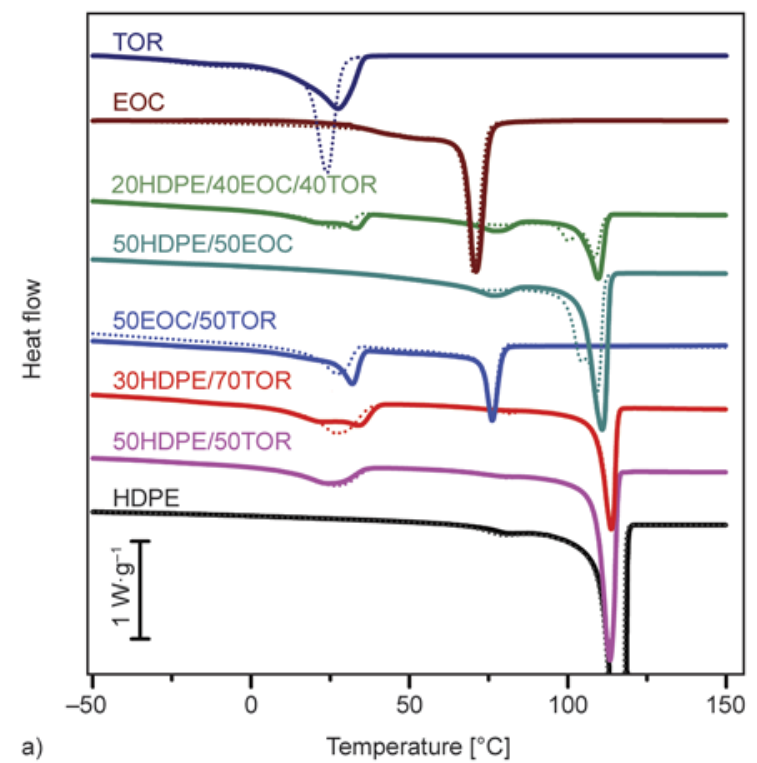

and crystalline HDPE/EOC30 phases due to thermodynamic incompatibility between TOR and polyethylenes.

Melting $\left(T_{\mathrm{m}}\right)$ and crystallization $\left(T_{\mathrm{c}}\right)$ temperatures of HDPE phase decrease at decreasing HDPE content in EBR cross-linked blends compared to values for bulk cross-linked HDPE similarly as it was observed for HDPE/EOC30 blends cross-linked by peroxide [12]. At the same time, $T_{\mathrm{m}}$ and $T_{\mathrm{c}}$ values for EOC30 phase can increase in blends containing HDPE. If the increase of $T_{\mathrm{c}}$ and correspondingly $T_{\mathrm{m}}$ values of EOC30 can be explained as a result of the nucleating effect of crystallites in cooling run, both decrease of $T_{\mathrm{c}}$ and $T_{\mathrm{m}}$ values of HDPE as well as a multiple melting and fractionated crystallization behavior point indirectly at a significant molecular interaction of EOC30 and HDPE blends in molten state but solely in regions where the molecular level of mixing before cross-linking was achieved. Overlapped melting peaks obtained from DSC investigations for HDPE/EOC30 blends support the idea of weak phase separation due to the thermodynamic compatibility between HDPE and EOCs.

Apparent specific heat capacity as a function of temperature obtained for HDPE/PCL blends crosslinked by $1.3 \mathrm{wt} \%$ of DHBP peroxide reveals well separated distinct peaks (Figure 6) caused by crystallization (a) and melting (b) of both PCL and HDPE phases at temperatures of about 40 and $110^{\circ} \mathrm{C}$ as well as 50 and $120^{\circ} \mathrm{C}$, respectively.

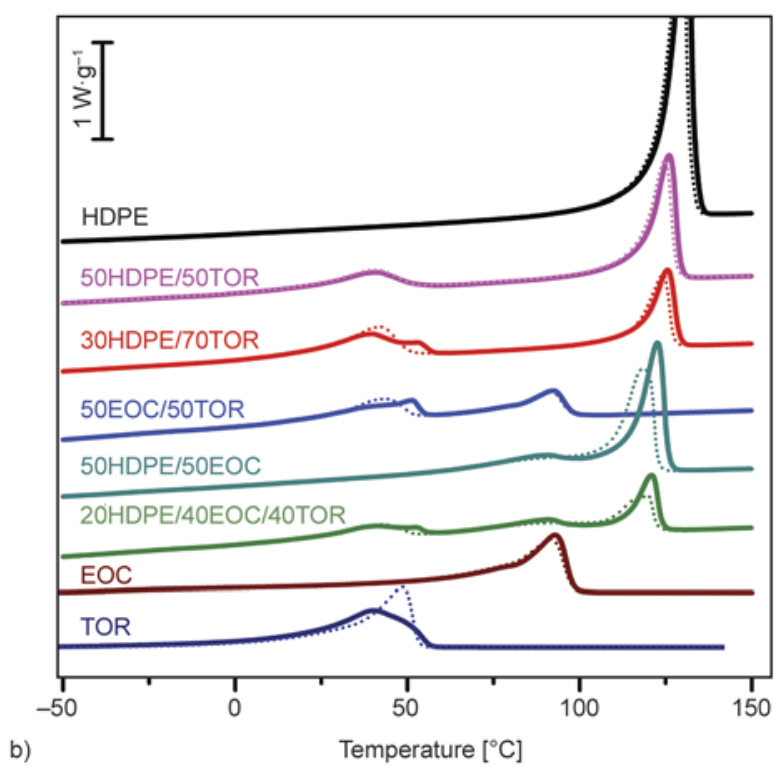

Figure 5. DSC traces of HDPE, EOC30 and TOR as well as their different binary and ternary blends, which were slowly cooled ( $s c-$ thick solid lines) or quenched $\left(q-\right.$ thin dotted lines) before HEE cross-linking, obtained during $1^{\text {st }}$ cooling (a) and $2^{\text {nd }}$ heating (b) runs [13] 

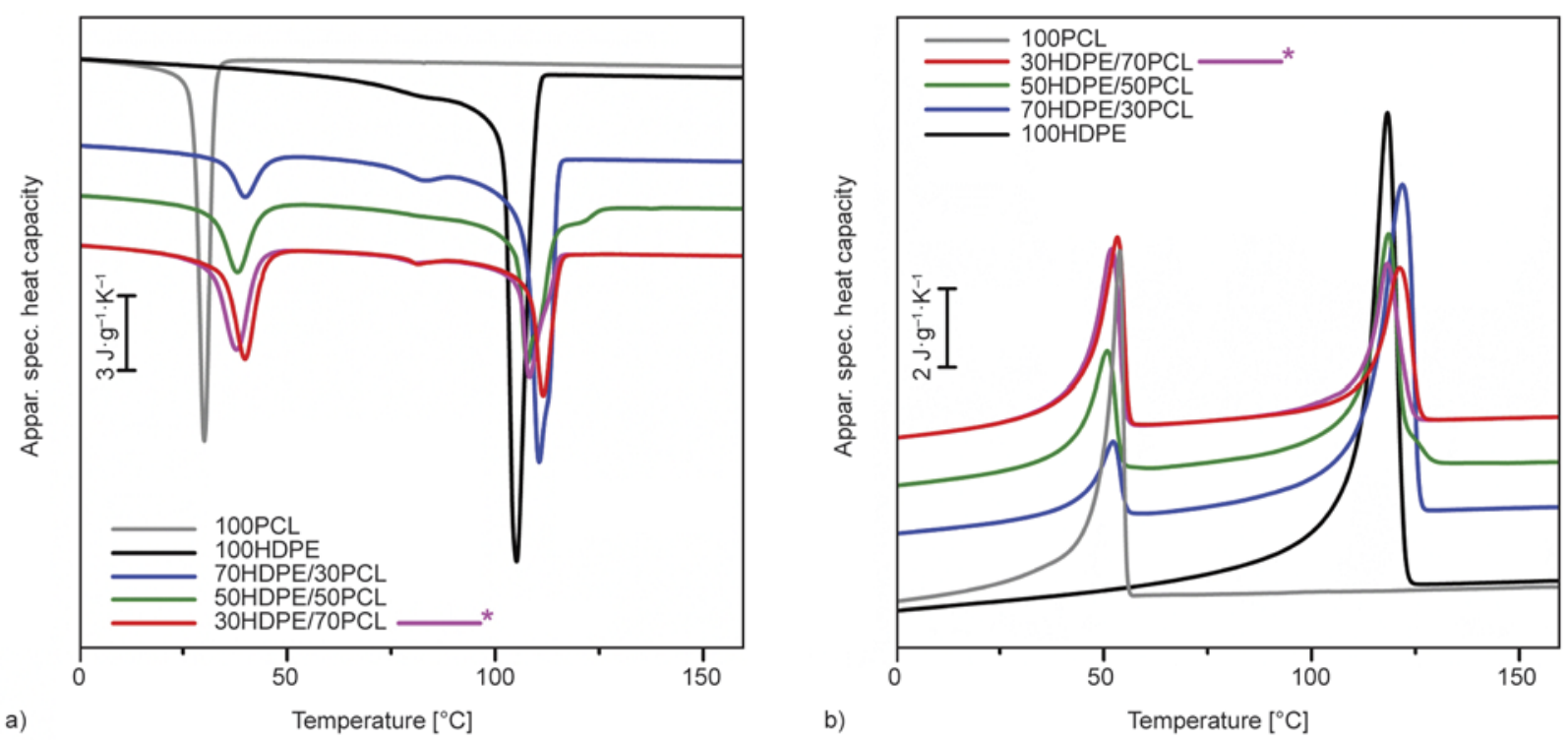

Figure 6. Apparent specific heat capacity as a function of temperature obtained for HDPE, PCL and their binary blends crosslinked by $1.3 \mathrm{wt} \%$ of DHBP, which demonstrate crystallization (a) and melting (b) of both PCL and HDPE phases. The magenta curves marked by asterisk present the 30HDPE/70PCL blends cross-linked by $2.0 \mathrm{wt} \%$ of DHBP.

Note that crystallization peak temperature $T_{\mathrm{c}}$ of bulk PCL is markedly lower than those of PCL phase in blends. This peculiarity can be explained by crystallization of PCL phase in the presence of already crystallized HDPE phase due to nucleating effect. At the same time, it is difficult to explain the lower $T_{\mathrm{c}}$ and $T_{\mathrm{m}}$ values of bulk HDPE compared to those of HDPE phase in blends by reason that during non-isothermal crystallization of HDPE phase in HDPE/PCL blends the PCL phase remains in amorphous state. It can be only assumed that PCL is a source of some nucleating impurities, which pollute the HDPE phase during the mixing process [48].

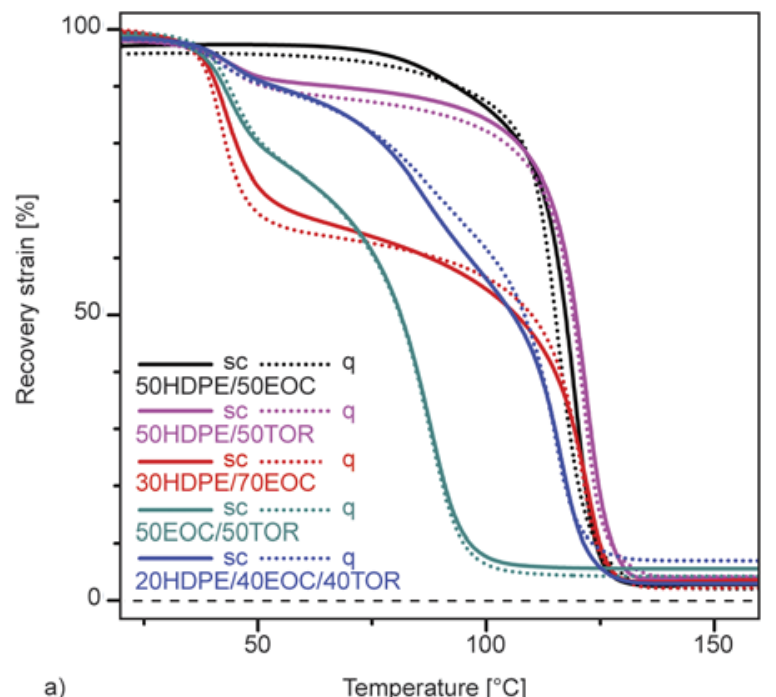

\section{One-way SM behavior of heterogeneous SM polymer networks}

Special thermo-mechanical tests were applied to investigate the multiple SM behavior in PEs/TOR blends. Temperature dependences of SM recovery strain $\left(\varepsilon_{\text {rec }}\right)$ and SM recovery rate obtained using time derivative of recovery strain $\left(-\mathrm{d} \varepsilon_{\mathrm{rec}} / \mathrm{d} t\right)$ are presented in Figure 7. Preliminary investigations of phase morphology pointed out that TOR owning the lowest melting temperature compared to other components is the continuous phase (matrix) of blends. Therefore, the TOR continuous phase with the lowest melting temperature does not constrain the SM recovery by

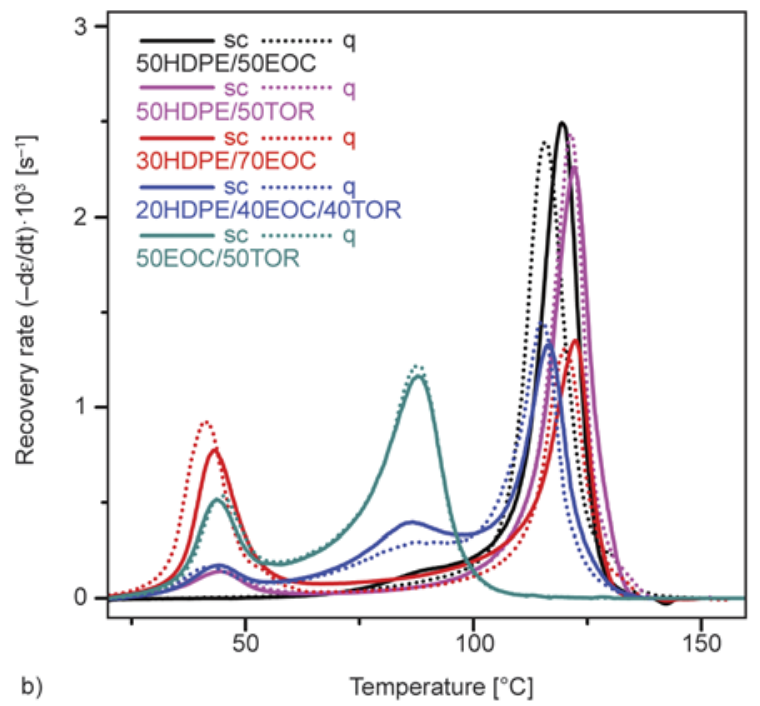

Figure 7. SM recovery strain (a) and SM recovery rate (b) of different binary and ternary blends on the basis of HDPE, EOC30 and TOR as function of temperature. The slowly cooled ( $s c-$ solid lines) and quenched ( $q$ - dotted lines) specimens were cross-linked by HEE. 
melting of the disperse phase/-s. As a result, the blends on the basis of TOR forming the continuous phase evince a pronounced multiple SM behavior (see Figure 7). The SM blends cross-linked by HEE show high values of strain fixing and strain recovery ratios of 95 to $99 \%$.

The HDPE/TOR and EOC30/TOR blends of $q$ preparation demonstrate more pronounced triple-shape behavior in comparison to blends of $s c$ preparation that is reflected also by the higher peak values of SM recovery rate in particular of the TOR phase (see Table 4). Such triple-shape behavior correlates with finer phase separation and better phase segregation in blends of $q$ preparation. Ternary 20HDPE/40EOC30/ 40TOR blend demonstrates some blurred indistinct quadruple-shape behavior. However, the detected temperature dependencies of SM recovery strain and rate allow to single out three steps and three peaks, respectively, in temperature ranges of melting of the continuous and both disperse phases.

The results of SM behavior investigation for HDPE, PCL, and HDPE/PCL blends cross-linked by $1.3 \mathrm{wt} \%$ of DHBP (see Figure 8) received during one-way unconstrained SM experiments demonstrate the pronounced triple-shape memory effect - two distinct steps of SM recovery strain at temperatures of above 53 and $121^{\circ} \mathrm{C}$ - in case of 30HDPE/70PCL blend, whose HDPE phase having higher melting and crystallization temperatures is dispersed in the continuous PCL phase/matrix.

The kinetics of unconstrained one-way SME as well as the switching temperatures $\left(T_{\mathrm{sw}}\right)$ of cross-linked

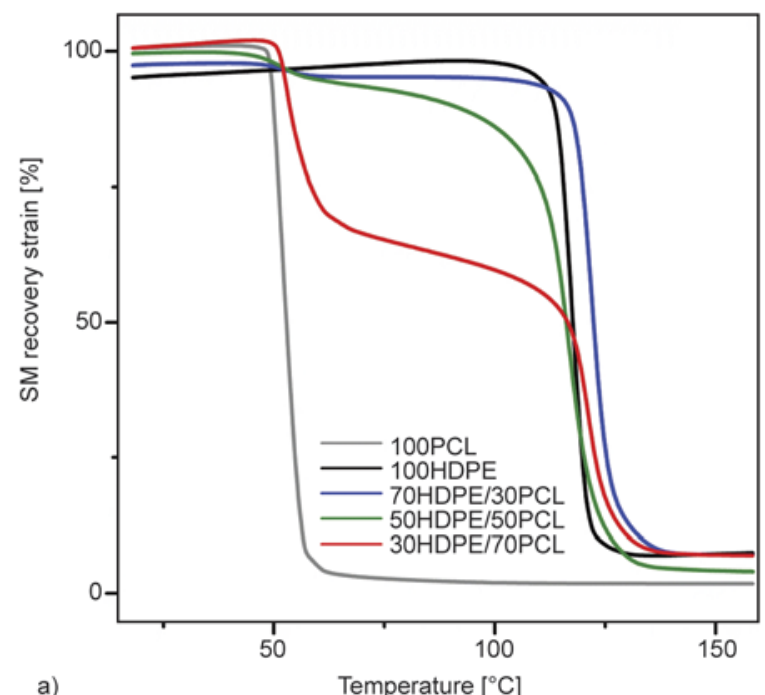

HDPE, PCL as bulk materials and as components of their blends have been estimated on the basis of peak values of SM recovery rate $\left(\left[-\mathrm{d} \varepsilon_{\mathrm{rec}} / \mathrm{d} t\right]_{\max }\right)$ and temperatures, at which these $\left[-\mathrm{d} \varepsilon_{\text {rec }} / \mathrm{d} t\right]_{\max }$ values arise, respectively.

These data along with $T_{\mathrm{c}}$ and $T_{\mathrm{m}}$ values obtained by DSC experiments are presented in Table 4 and demonstrate very good accordance between $T_{\mathrm{m}}$ and $T_{\mathrm{Sw}}$ values as well as a considerable deceleration of SM recovery kinetics of PCL and HDPE phases in blends in comparison with bulk PCL and HDPE, which is exceedingly high for PCL phase dispersed in continuous HDPE phase having higher $T_{\mathrm{m}}$. Thus, thermally induced macroscopic shape change of blends caused by SM recovery of each separate blend phase is restricted by other phases and especially by immobilized solidified phase, particularly when this solidified phase is continuous.

Note that all networks under study and in particular PCL show very high value of strain fixing $\left(R_{\mathrm{f}}\right)$ and strain recovery $\left(R_{\mathrm{r}}\right)$ ratios (see Table 4 ).

\section{Two-way SM behavior of heterogeneous SM polymer networks \\ 6.1. Singular two-way SM behavior}

Invertible two-way SM effect can be observed in each crystallizable polymer network if the suitable $v_{\mathrm{c}}$ and load values are chosen $[7-9,17]$. The results demonstrated in Figure 9 prove that HDPE cross-linked by peroxide is not an exception to this statement [48].

As can be seen from Figure 9a, the anomalous macroscopic elongation of a sample under constant

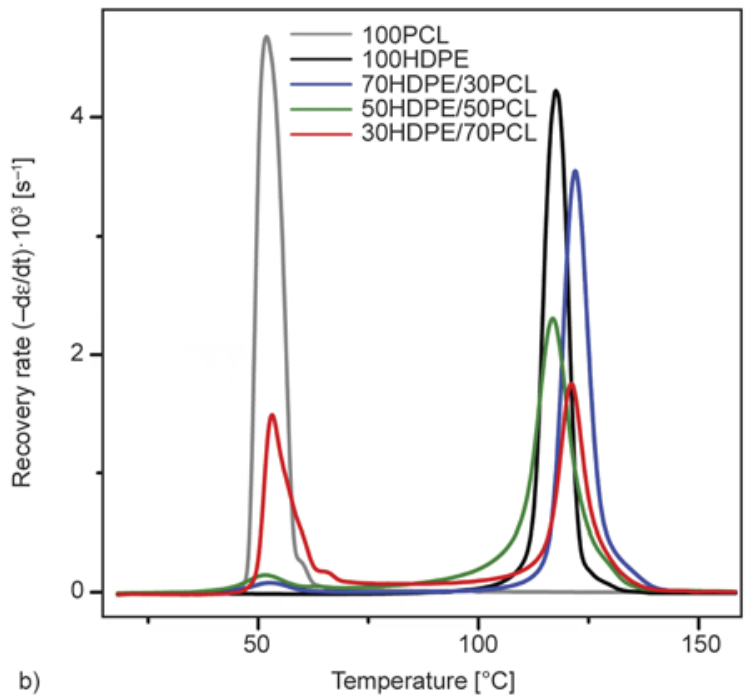

Figure 8. Temperature dependence of SM recovery strain (a) and SM recovery rate (b) for HDPE, PCL, and HDPE/PCL blends cross-linked by $1.3 \mathrm{wt} \%$ of DHBP. One-way unconstrained SM experiment performed after programming at $170^{\circ} \mathrm{C}$ and constant strain of $100 \%$ [48]. 


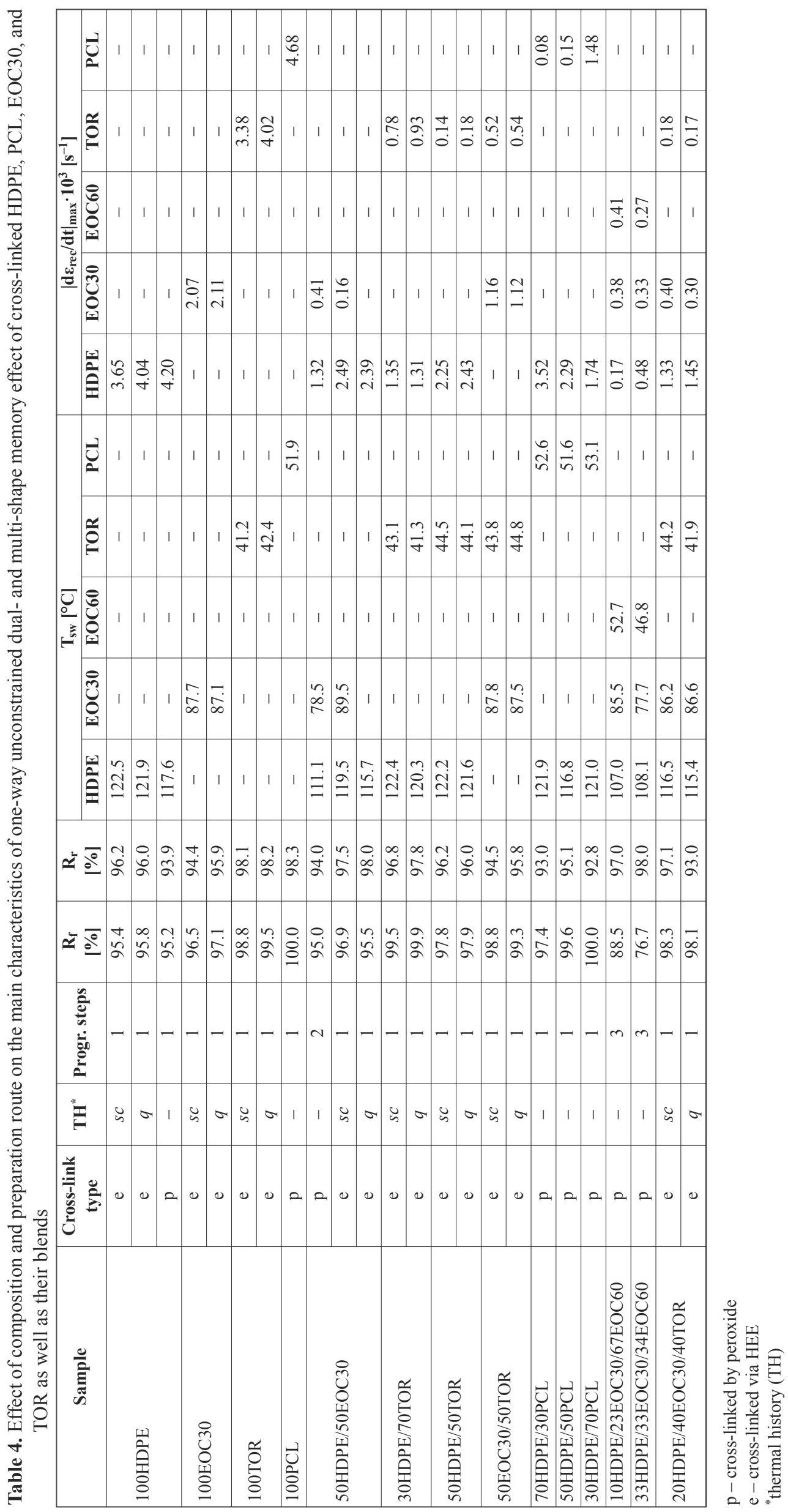



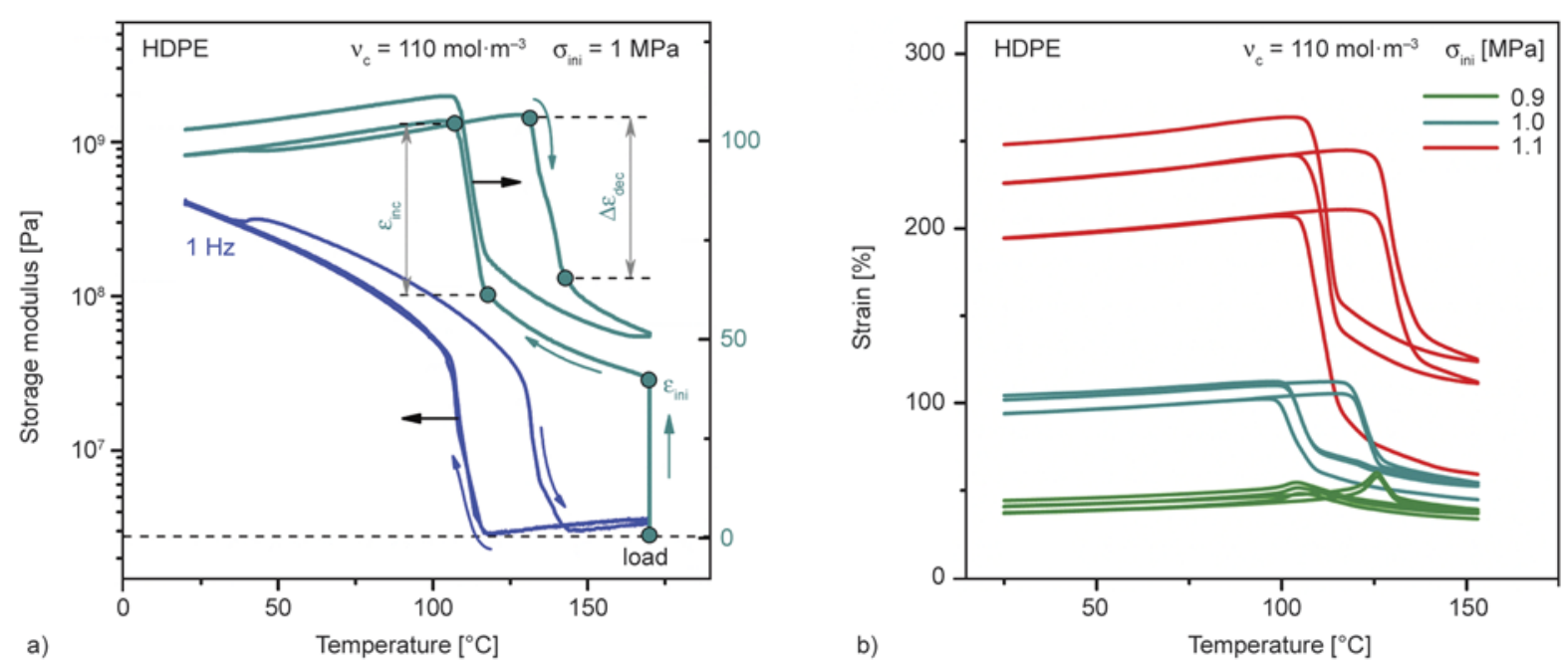

Figure 9. Temperature dependences of SM creep and recovery strain measured simultaneously along with dynamicmechanical storage modulus under constant load with initial stress $\left(\sigma_{\text {ini }}\right)$ of $1 \mathrm{MPa}($ a) and in cyclic two-way SM experiments carried out under three different $\sigma_{\text {ini }}$ values (b) obtained for HDPE cross-linked by DHBP [48]

load is accompanied with simultaneous distinct increase of storage modulus during non-isothermal crystallization of the covalent polymer network, which is expected due to the increase of crystallinity. The repeating thermal cycling reveals good reproducibility for networks with relatively high crosslink density (Figure 9b). Generally, the repetition of thermal two-way SM cycles results in a tendency to improve reproducibility of SM cycling/ performance similar to the thermomechanical "training' treatment of SM alloys [49].

Temperature dependences of SM creep and recovery strain of HDPE obtained during two-way SM

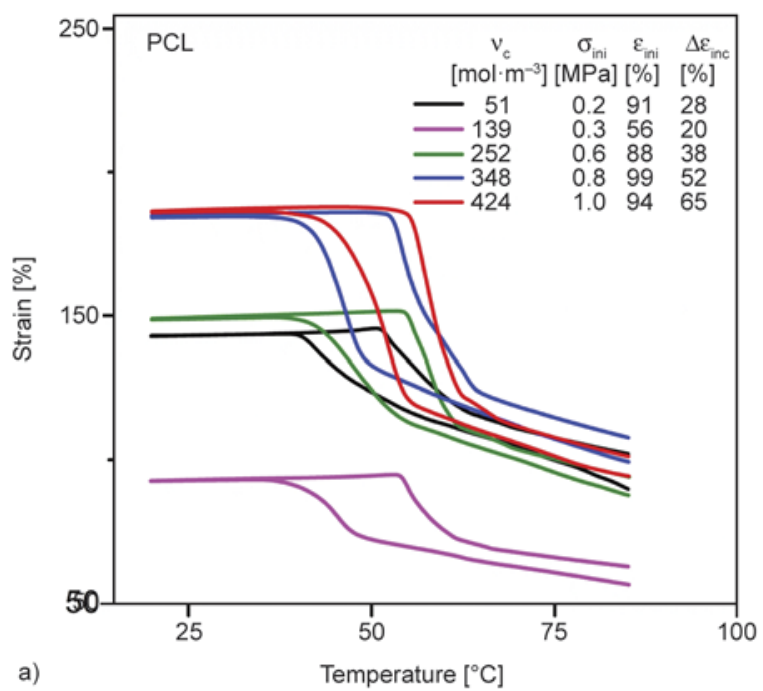

experiment at different load values (loading temperature of $\left.165^{\circ} \mathrm{C}\right)$ point to an increase of the strain increment $\left(\Delta \varepsilon_{\text {inc }}\right)$ with increasing load. However, load with initial stress $\left(\sigma_{\text {ini }}\right)$ lower than $1 \mathrm{MPa}$ is not sufficient to observe the anomalous elongation. On the contrary, HDPE sample under load of $0.9 \mathrm{MPa}$ shrinks during crystallization, as it is normally expected. Thus, it can be concluded that the different polymer networks show very different threshold values of initial stress (constant force) required for the convenient occurrence of two-way SME that is definitely affected by crosslink density and crystallizability of the covalent polymer network.

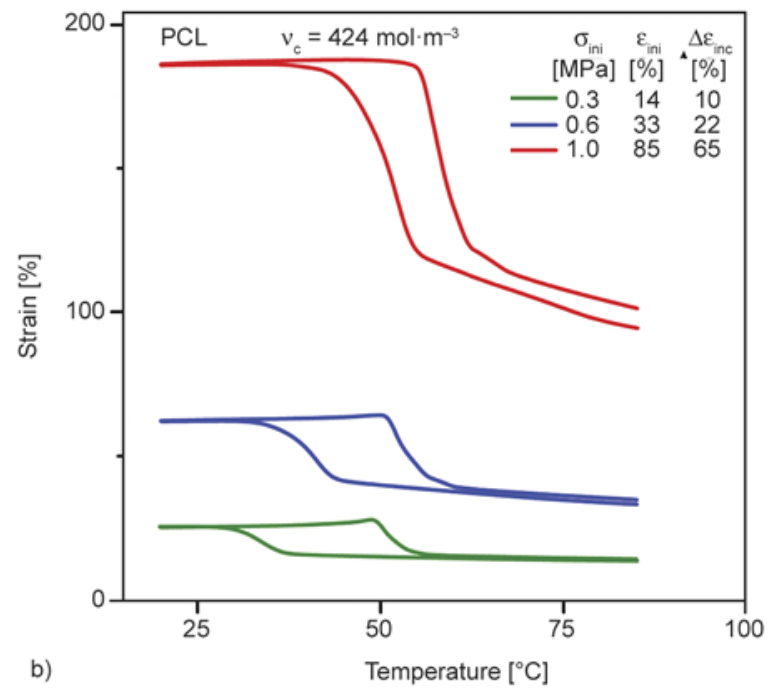

Figure 10. Temperature dependences of SM creep and recovery strain measured in the first cycle of two-way SM experiments using PCL cross-linked by different amounts of DHBP (a) and PCL with $v_{\mathrm{c}}=424 \mathrm{~mol} \cdot \mathrm{m}^{-3}$ under different permanent loads (b). Conditions of experiments and main parameters of performed two-way SM experiments are given in legends [48]. 
Temperature dependences of SM creep and recovery strain obtained during two-way SM experiment after loading performed at $100^{\circ} \mathrm{C}$ for PCL with different crosslink density $v_{\mathrm{c}}$ and PCL with $v_{\mathrm{c}}=424 \mathrm{~mol} \cdot \mathrm{m}^{-3}$ under load with different initial stress shown in Figure 10 point to an increase of the crystallizationinduced strain increment $\left(\Delta \varepsilon_{\text {inc }}\right)$ and of the meltinginduced strain decrement $\left(\Delta \varepsilon_{\mathrm{dec}}\right)$ as well as to a decrease of the initial strain after load $\left(\varepsilon_{\text {ini }}\right)$ with increasing $v_{\mathrm{c}}$. The SM creep strain increment for PCL samples with enough high $v_{\mathrm{c}}$ values gains with increasing load (see Figure 10b).

\subsection{Triple two-way SM behavior}

Temperature dependences of SM creep and recovery strain depicted in Figure 11 for binary HDPE/ PCL blends cross-linked by $1.3 \mathrm{wt} \%$ of DHBP and 30HDPE/70TOR blend cross-linked by high energy electrons with dose of $200 \mathrm{kGy}$, which were obtained in the course of two-way SM experiment, demonstrate invertible triple-shape memory effect [4], which is more distinct for 30HDPE/70PCL and 30HDPE/ 70TOR blends, similar to one-way SM experiment [13].

The occurrence of two-way SM creep and recovery strain steps related to HDPE phase at $\sigma_{\text {ini }}$ values less than $1 \mathrm{MPa}$ is presumably explained by inhomogeneous distribution of load to blend phases. The local stress in areas of the HDPE phase possessing an enhanced modulus of elasticity is apparently considerably higher in comparison with nominal macroscopic stress applied to the sample.

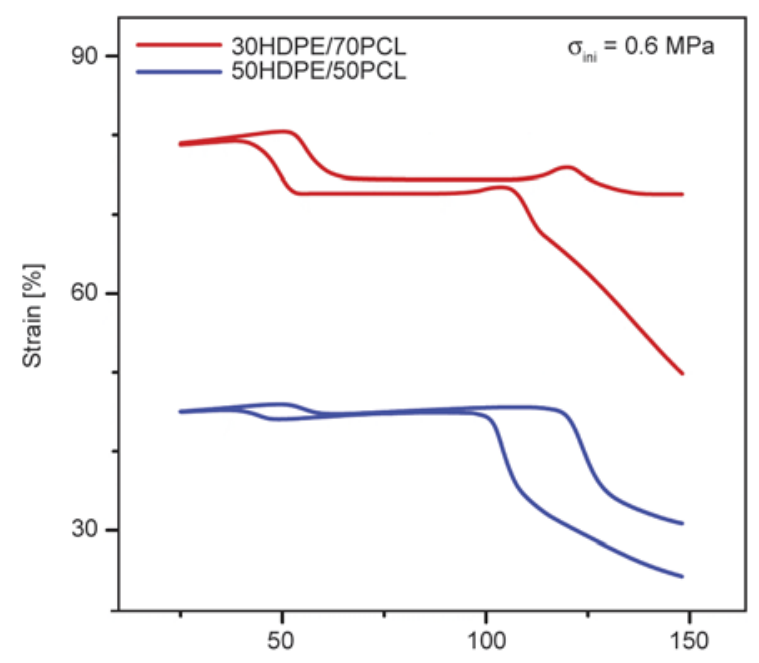

a)

Temperature $\left[{ }^{\circ} \mathrm{C}\right]$
In order to achieve a triple-shape behavior with requested performances, for instance comparable $\Delta \varepsilon_{\text {ind }} / \Delta \varepsilon_{\text {dec }}$ values for both SM strain steps, the crosslinkability and crystallinity of blend components should be taken into account because they are immediately responsible for the driving forces of SM creep and recovery. It also has to make allowance for mobility constraints, which are produced by the fixed semi-crystalline phase on the blend phase having lower $T_{\mathrm{m}}$ and $T_{\mathrm{c}}$ during its melting/crystallization. The considerably higher driving forces and correspondingly sufficient values of crosslink density and load are required for the characteristic sample shape change caused by the phase mobility with lower $T_{\mathrm{m}} / T_{\mathrm{c}}$. In this connection, the 50EOC $30 /$ 50TOR blend is obviously a more suitable subject of such discussion because of peculiarity of phase morphology, comparable crystallinity of blend phases and enhanced cross-linkability of the TOR matrix based on the presence of double bonds regularly spaced along the polymer chains [50]. As may be clearly seen from Figure 11b (bottom), the 50EOC30/50TOR blend demonstrates pronounced triple-shape behavior with considerable but at the same time comparable $\Delta \varepsilon_{\text {inc }}$ and $\Delta \varepsilon_{\text {dec }}$ values connected with elongation and contraction of EOC30 and TOR blend phases, respectively.

The data presented in this section allow concluding that both one- and two-way multiple SM effect can be also achieved in covalent networks on the basis of polymer blends, if a suitable phase morphology is able to be generated. For blends of linear or short-

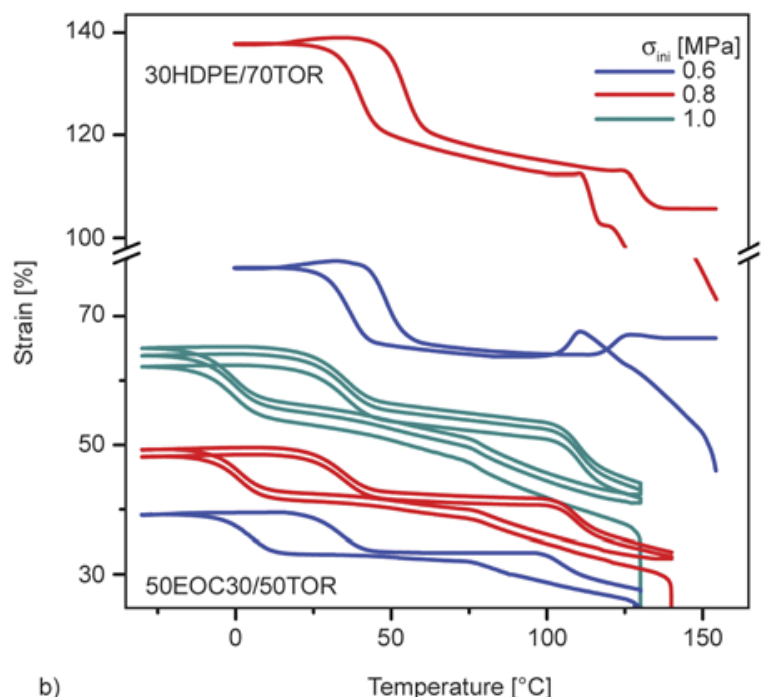

b)

Figure 11. Temperature dependences of SM creep and recovery strain for binary HDPE/PCL blends (a), 30HDPE/70TOR, and 50EOC30/50TOR (b) blend obtained in the course of two-way SM experiment [48] 
chain branched polyethylenes and poly( $\varepsilon$-caprolactone) (PCL) or trans-polyoctenamer (TOR) crosslinked by peroxide an appreciable triple-shape memory behavior with relatively good performances has been observed. The two-way SME performance in crystallizable covalent polymer networks gains with increasing crystallinity and crosslink density. In the special case of triple-shape behavior of polymer blends the situation becomes more complicated because of presumably inhomogeneous distribution and unlike efficiency of crosslinking agent in polymer blend components, which cannot be excluded. For this reason the obtainment of comparable values of crosslink density and normalized crystallinity defined as product of crystallinity and content of components for all blend phases is also very important. Thus, similar to one-way SME the key to proper occurrence and further improvement of the multiple two-way SM behavior of polymer blends is the generation of a well defined phase morphology including the well-developed separation/decoupling of the blend phases and an optimization of this phase morphology.

\section{Modeling of SM behavior}

\subsection{Modeling of one-way SME}

Recently, a new theoretical approach based on the modified three-element Eyring-Halsey model with non-Newtonian dashpot shown in Figure 12 was developed for the derivation of an equation describing the thermally induced recovery of pre-deformed and crystallized cross-linked polymers, in other words, describing SM recovery during one-way SME $[50,51]$. The possibility of using such a model in case of creep/recovery process has been already pointed out in the works of Krausz and Eyring [53] and Ziabicki [54]. However, in the aforementioned study just non-isothermal recovery of preloaded (SM programmed) polymers is considered and the following specifications of elements in this model
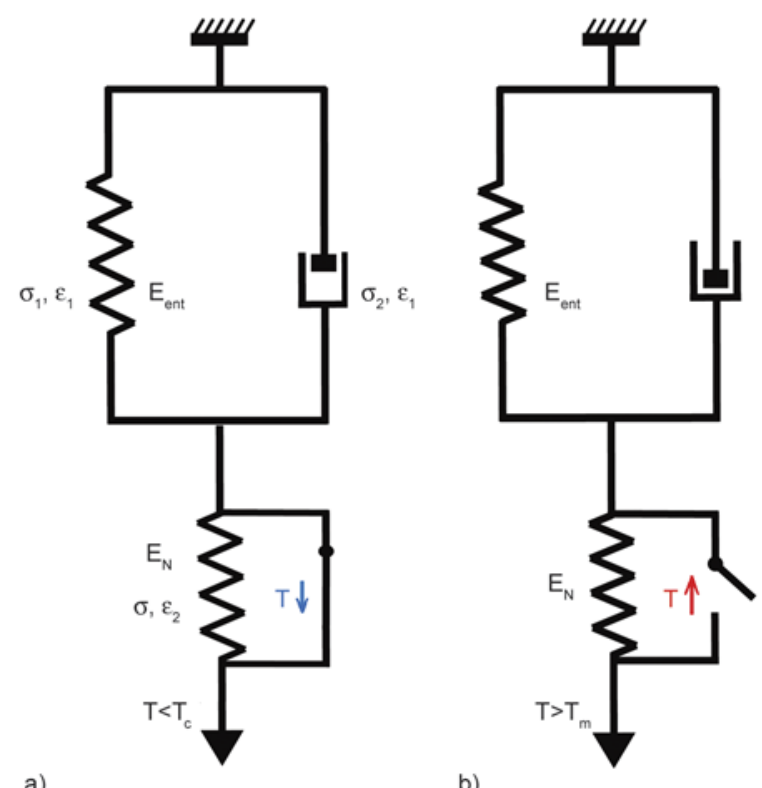

Figure 12. The three-element model proposed for the description of thermally induced recovery of semi-crystalline cross-linked polymers from deformed temporary (a) to a permanent shape (b) after heating above melting point [52]

are proposed. Firstly, a spring and a dashpot connected in parallel represent slipped entangled molecular chains containing loops and ends (Figure 12), but in contrast to Krausz and Eyring [53] another definition of the spring constant $E_{\text {ent }}$ was used. Secondly, crystallizable covalent network is represented by the second spring. In addition, a trigger switch is connected in parallel with the second spring in order to illustrate shape fixing (Figure 12a) and shape recovery (Figure 12b) of covalent network caused by its crystallization and melting, respectively. Thus, the model in Figure 12 accounts for two basic mechanisms involved in SM performance - crystallization/melting of covalent network as well as slipping of entangled macromolecules. Basing on the reasonable assumptions, the thermally induced recovery strain was derived as described by Equations (2)-(4):

$$
\begin{aligned}
& \varepsilon_{\mathrm{rec}}(T)=C_{0} \cdot T+\varepsilon_{1}+\varepsilon_{2} \\
& \varepsilon_{1}=\frac{8}{3 V_{\mathrm{h}} \nu_{\mathrm{e}} N_{\mathrm{A}}} \tanh ^{-1}\left[\tanh \left(\frac{3}{8} V_{\mathrm{h}} \nu_{\mathrm{e}} N_{\mathrm{A}} \varepsilon_{01}\right) \cdot \exp \left(\frac{3 V_{\mathrm{h}}^{2}}{4 V_{\mathrm{m}}} \frac{\nu_{\mathrm{e}} U}{\alpha h} T \cdot \exp \left(-\frac{U}{R T}\right) \cdot\left[\frac{R T}{U}-2\right]\right)\right] \\
& \varepsilon_{2}=\varepsilon_{\mathrm{pr}}-\varepsilon_{01}+\frac{4 C_{2}^{0} \cdot(1-A)}{\nu_{\mathrm{c}} R}-\frac{4 C_{2}^{0 \cdot}\left[A \cdot \exp \left(-K\left(\frac{T}{T_{\mathrm{sw}}}\right)^{\mathrm{m}}\right) \cdot\left(\frac{3}{2} \nu_{\mathrm{c}} R T-E_{\mathrm{i}}\right)+E_{\mathrm{i}}\right]}{\nu_{\mathrm{c}} R E_{\mathrm{i}}}
\end{aligned}
$$


where physical and material constants are: $N_{\mathrm{A}}$ - the Avogadro constant, $h$ - the Planck constant, $\alpha$ - heating rate, $R$ - the gas constant, $\varepsilon_{\mathrm{pr}}-$ the programming strain, $v_{\mathrm{c}}$ is the crosslink density, $T_{\mathrm{sw}}-$ the switching temperature of SM recovery. The values of material constants were determined by means of appropriate experimental investigation. The list of used fitting parameters and their definitions is given in Table 5. The modeling of thermally induced SM recovery strain and SM recovery rate detected at constant heating rate of $2 \mathrm{~K} \cdot \mathrm{min}^{-1}$ has been successfully performed on the basis of Equations (2)-(4) for crosslinked HDPE, EOC30, and EOC60. The results of modeling presented in Figure 13 demonstrate excellent coincidence between experimental and fitting curves. The values of material constants determined by fitting well agree with their estimations existing in literature and allow concluding that:

- crystallization plays a key role in SME of PEs under study;

- in high crystalline HDPE the crystallization of network is a dominant mechanism in SM recovery;

- decrease of the ability to crystallization in EOC30 and EOC60 leads to an increase of contribution of entangled slipped molecular chains to SM performance.

\subsection{Modeling of two-way SME}

The three-element mechanical model shown in Figure 12 was also employed to describe two-way SME [55]. However, it is emphasized that crystallizing/ melting covalent network plays a key role in two-

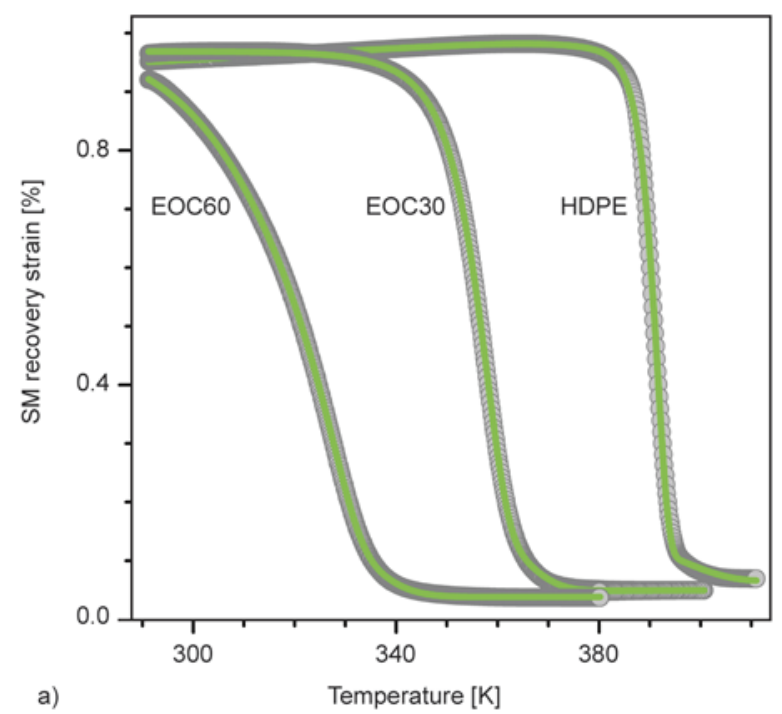

Table 5. Parameters used for fitting one-way SME as well as their definitions

\begin{tabular}{|c|c|c|c|}
\hline \multicolumn{2}{|r|}{$\begin{array}{c}\text { Effect of entangled slipped } \\
\text { molecules }\end{array}$} & \multicolumn{2}{|r|}{$\begin{array}{c}\text { Effect of melting covalent } \\
\text { network }\end{array}$} \\
\hline$V_{\mathrm{h}}$ & activation volume & $E_{\mathrm{i}}$ & $\begin{array}{l}\text { modulus corresponding to } \\
\text { the internal energetic defor- } \\
\text { mation }\end{array}$ \\
\hline$V_{\mathrm{m}}$ & $\begin{array}{l}\text { volume of the slipping } \\
\text { molecule }\end{array}$ & $A$ & crystallinity at $T \rightarrow 0$ \\
\hline$v_{\mathrm{e}}$ & $\begin{array}{l}\text { density of the entangled } \\
\text { molecules }\end{array}$ & $K$ & $\begin{array}{l}\text { material constant related to } \\
\text { the heating rate }\end{array}$ \\
\hline$U$ & activation energy & $m$ & $\begin{array}{l}\text { material constant related to } \\
\text { the rate of crystallization }\end{array}$ \\
\hline \multirow[t]{2}{*}{$\varepsilon_{01}$} & \multirow[t]{2}{*}{$\begin{array}{l}\text { strain stored by entangled } \\
\text { slipped molecules }\end{array}$} & $C_{2}^{0}$ & $\begin{array}{l}\text { coefficient responsible for } \\
\text { the deviation from the the- } \\
\text { ory of rubber elasticity }\end{array}$ \\
\hline & & $C_{0}$ & linear expansion coefficient \\
\hline
\end{tabular}

way SME being suggested responsible for the anomalous elongation of a sample under constant load during non-isothermal crystallization. A theory of the stress-induced crystallization of cross-linked polymers developed by Gaylord [56] was used to reconsider the theoretical description of the behavior of crystallizable covalent network represented by the second spring in Figure 12. Though derived theoretical approach is based on the Gaylord's theory, it allows calculating the free energy change of a sample deformed under constant load (not constant deformation) and cooled down below crystallization temperature $T_{\mathrm{c}}$ at a constant cooling rate, i.e. in non-isometric and non-isothermal conditions, respectively. The free energy of crystallization of semicrystalline network is written as shown by Equations (5)-(7):

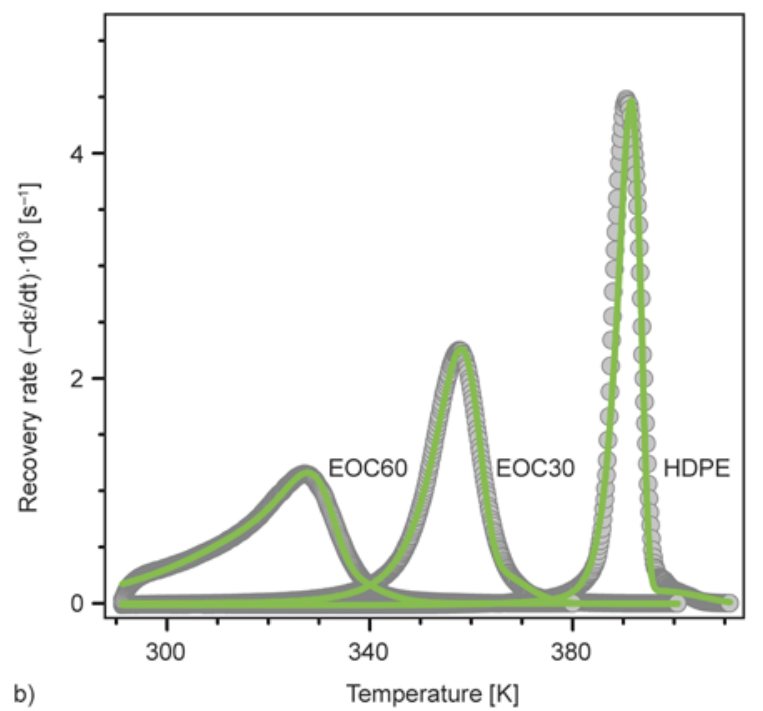

Figure 13. SM recovery strain (a) and SM recovery rate (b) for PEs with different degree of branching - HDPE, EOC30, EOC60. Grey points represent the experimental data, green lines represent the fitting results [52]. 


$$
\begin{aligned}
& \begin{array}{l}
\Delta F_{\mathrm{f}}\left(\chi_{\mathrm{c}}, T, \lambda\right)=-N \chi_{\mathrm{c}} \Delta H_{\mu}\left(1-\frac{T}{T_{\mathrm{m}}^{0}}\right)+U_{\mathrm{em}}+f U_{\mathrm{e}}+\frac{R T}{2 \theta}\left[1-\frac{1}{N \theta}\right] \cdot\left[\lambda^{2}-2 \varphi \delta\left(1+\frac{1}{20 N}\right) \lambda+\frac{2}{\lambda}+\frac{3 \varphi^{2}}{N}-3 \theta\right]+ \\
\quad \frac{3 R T}{20 N \theta^{3}}\left[\lambda^{4}+\frac{4}{3} \lambda+\frac{3 \varphi^{4}}{N^{2}}+\frac{8}{3} \frac{1}{\lambda^{2}}+\frac{6 \varphi^{2}}{N} \lambda^{2}+\frac{4 \varphi^{2}}{N} \frac{1}{\lambda}-\frac{8}{3} \varphi \delta\left(\lambda^{3}+1\right)-\frac{4}{N} \varphi^{3} \delta \lambda-\theta^{2}\left(5-\frac{2}{N \theta}\right)\right] \\
\theta=\left(1-\chi_{\mathrm{c}}-\frac{\psi f}{N}\right) \\
\varphi=\left(\frac{f^{2} a^{2}}{b^{2}}+\beta \zeta^{2}\right)^{1 / 2}, \begin{array}{l}
\beta \\
\beta
\end{array}=0, \text { odd folds }
\end{array}
\end{aligned}
$$

where $N$ is the number of chain links, $\Delta H_{\mu}$ is the enthalpy of fusion per link, $U_{\mathrm{em}}$ and $U_{\mathrm{e}}$ are the free energy of the interface between amorphous and crystalline regions and the surface free energy of a crystal with $f$ folds, each with $\psi$ links, respectively, $T_{\mathrm{m}}^{0}$ is the equilibrium melting temperature, $a$ is the chain thickness, $b$ is the length of a chain link, $\zeta$ is the number of links traversing the crystallite, $\chi_{\mathrm{c}}$ is the crystallinity.

Following Gaylord, it was assumed that the number of crystal folds $f$ controls the orientation of crystallites formed during the two-way SME with respect to the applied force. Namely, the even number of folds results in perpendicular orientation of chains in crystal to the external force, while odd number of folds corresponds to the case when the orientation of chains in crystal is parallel to the stretch direction or makes a sharp angle with the external force. The free energies of crystallization as a function of temperature and draw ratio calculated for crosslinked HDPE on the basis of derived equations in case of different values of chain links $N$ and different

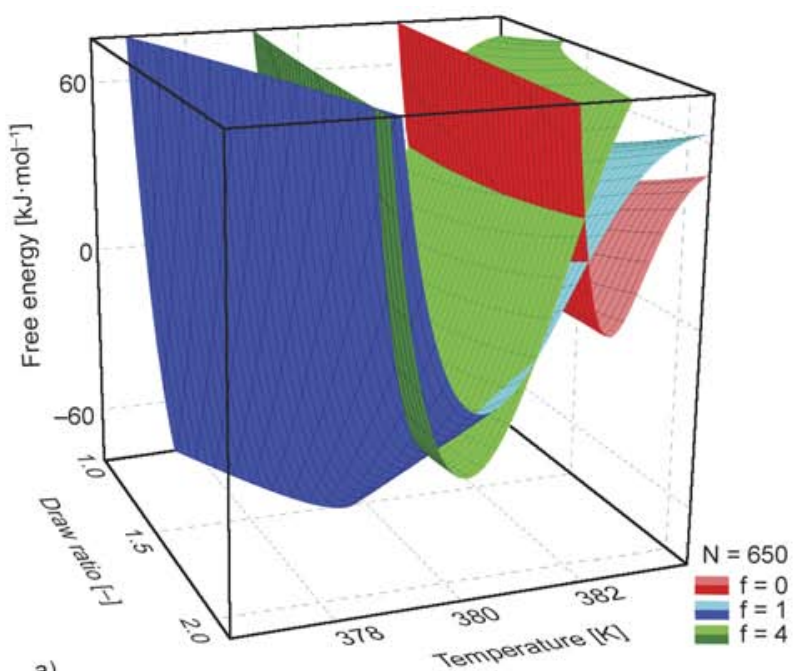

numbers of crystal folds $f$ are plotted in Figure 14. The results indicate that for given numbers of chain links the extended-chain morphology $(f=0)$ has a lower free energy at the onset of crystallization, and further cooling results in forming the folded-chain crystals oriented nearly parallel $(f=4$, Figure 14a) or perpendicular to the stretch direction $(f=1$, Figure 14b). Evidently, these different cases of crystal orientation lead to dramatically different mechanical behavior of pre-deformed crystallizing covalent network. The theory predicts that perpendicular orientation of chain folds in crystals results in sample contraction during crystallization, as expected, whereas anomalous elongation of a sample under load during two-way SME can be observed when crystal chains are nearly parallel to the force direction.

The stress-strain-temperature relationship derived from the free energy change was used to fit the experimental findings of the temperature dependent strain under load, which were received by the authors for cross-linked HDPE loaded by $1 \mathrm{MPa}$, as

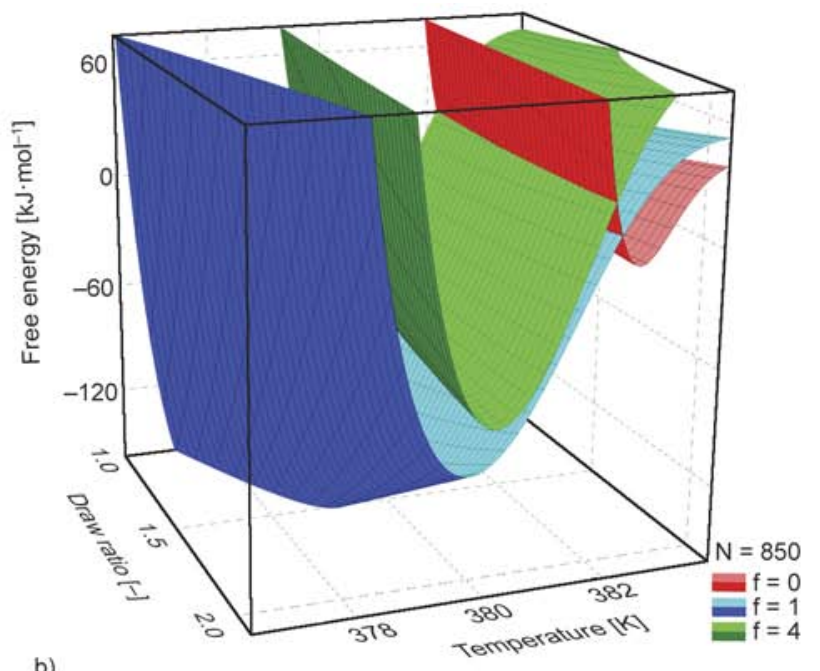

Figure 14. The free energy of crystallization as a function of temperature and draw ratio calculated for HDPE in case of different values of chain links $N=650$ (a), $N=850$ (b), and different numbers of crystal folds $f$ [55] 


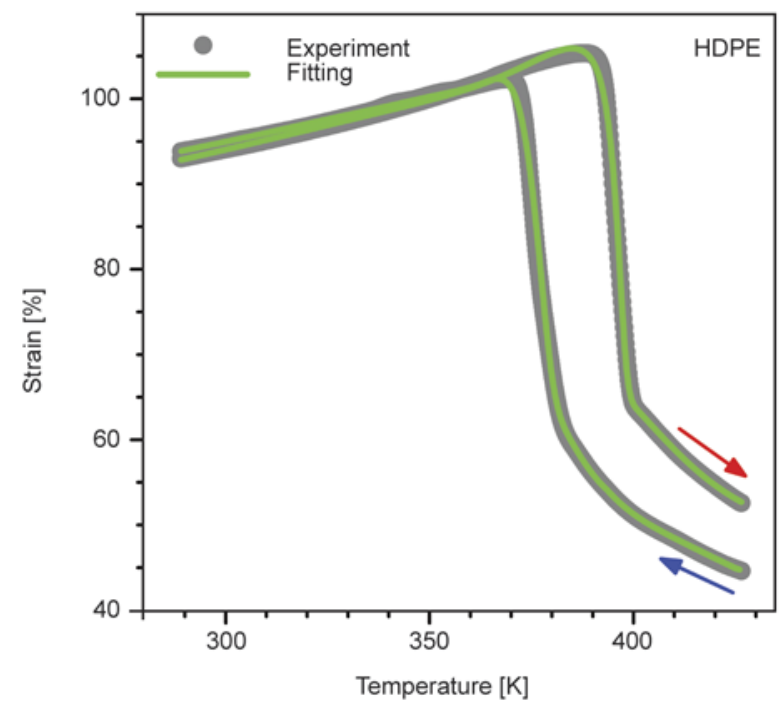

Figure 15. Fitting and experimental curves of two-way SME obtained for cross-linked HDPE loaded by $1 \mathrm{MPa}$. Blue and red arrows indicate cooling and heating runs, respectively [55].

shown in Figure 15. The fitting curves have shown excellent accordance with the experimental values. The fitting parameters used for the effect of entangled slipped macromolecules include all those listed in Table 5. Since the theoretical description of crystallizing/melting covalent network has been reconsidered, the corresponding fitting parameters are the number of chain links $N$, number of crystal folds $f$, crystallinity values $\chi_{\mathrm{c} 0}$ and $\chi_{\mathrm{cf}}$ corresponding to the lowest free energies of crystals with 0 and $f$ folds, respectively, and linear expansion coefficient. Although presented modeling the one- and two-way SME has been performed for single polymers, like

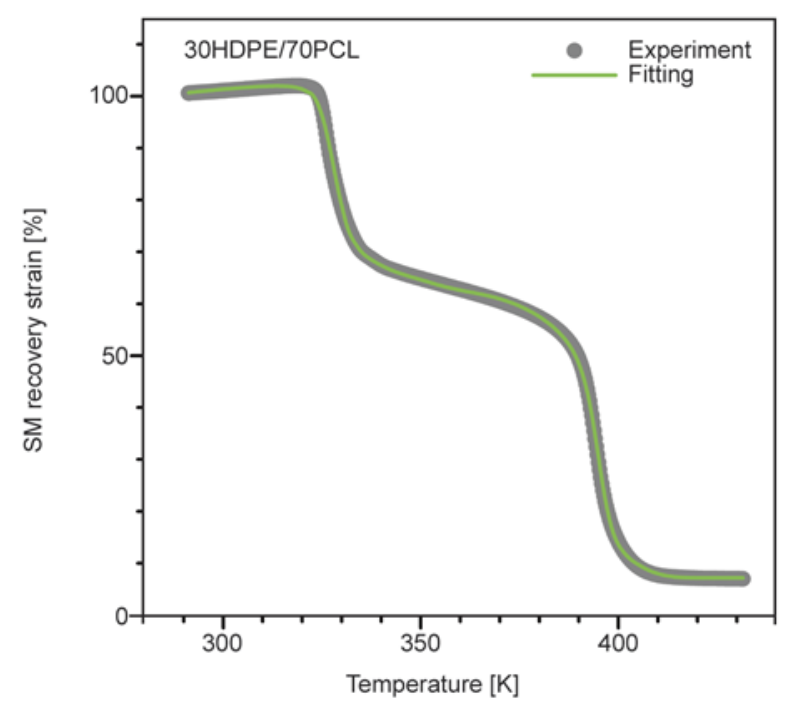

Figure 16. Fitting and experimental curves of multiple SM recovery obtained for cross-linked 30HDPE/ 70PCL blend
HDPE, EOC30, and EOC60, it opens broad prospects for modeling the SM phenomena in cross-linked blends of crystallizable polymers. First of all, the theoretical approach described above is accurate, physically grounded, and focused on the basic molecular mechanisms involved in one- and two-way SM behavior of both single polymers and polymer blends. In order to model the SM performance of polymer blends on the basis of presented theory, an account of phase morphology and its appropriate theoretical description are only needed. A potential of the present theoretical approach in modeling the one-way multiple SM behavior of cross-linked blends was verified for 30HDPE/70PCL blend. As it is seen from Figure 16, the fitting curve good coincides with the experimental findings. This encourages further development of the theory.

\section{Conclusions}

This mini-review about the generation and investigation of SM polymers on the basis of heterogeneous semi-crystalline polymer blends shows that such an approach has a great future potential. As an alternative to expensive synthesis of complex interpenetrating or block-copolymers networks both the one-way and two-way multiple SM effect can be also achieved in covalent networks on the basis of polymer blends, if a suitable phase morphology is able to be generated. For blends of crystallizable polymers covalently cross-linked by peroxide or electron irradiation an appreciable multiple-shape memory behavior with relatively good performances has been observed.

The main characteristics of both one-way and twoway SME in crystallizable covalent polymer network gain with increasing crystallinity and crosslink density. In the specific case of triple-shape behavior of polymer blends the situation becomes more complicated because of possible inhomogeneous distribution and efficiency of crosslinking agent in polymer blend components that cannot be excluded. For SM blends with high performance the obtainment of equal crosslink density and sufficient high crystallinity, which can be achieved by controlled technology of melt mixing, cooling, and cross-linking, is required.

The key to proper occurrence and further improvement of the multiple SM behavior of polymer blends is the generation of phase morphology including a well developed separation/decoupling of the blend 
phases and an optimization of this phase morphology. Especially, the distinct manifestation of tripleSM behavior is possible only when the continuous phase of the blend has lower crystallization/melting temperatures in comparison to the disperse phase.

The developed theoretical approach enabled not only the consistent and reliable description of the strain as a function of temperature obtained experimentally in the course of one- and two-way SME in crystallizable polymers but also the explanation of the anomalous elongation of crosslinked polymers under constant load during non-isothermal crystallization in terms of both crystal morphology and crystal orientation. Simultaneously, modeling of SME in heterogeneous networks on the basis of polymer blends requires the consideration of their phase morphology and of interaction of blend components using a suitable mechanical model.

Further investigation on the effect of phase morphology on mechanical properties and peculiarities of the SM behavior of covalent networks on the basis of crystallizable polymer blends will enable the optimization of their multiple SM behavior. The investigation of constrained SME and especially the SM recovery of polymer networks loaded by constant forces could help to estimate the dynamic behavior of SME and in particular to evaluate the specific stored mechanical energy. On the basis of such a study on the capability of a SM network to accumulate mechanical energy, routes could be formulated to create energy storage devices in future. Development of theoretical description of SM polymer materials can point the operating ways to improve SM behavior of polymer networks by means of tailoring of their structure and morphology.

\section{References}

[1] Lendlein A., Kelch S.: Shape-memory polymers. Angewandte Chemie International Edition, 41, 2034-2057 (2002).

DOI: 10.1002/1521-3773(20020617)41:12<2034::AIDANIE2034>3.0.CO;2-M

[2] Liu C., Qin H., Mather P. T.: Review of progress in shape-memory polymers. Journal of Materials Chemistry, 17, 1543-1558 (2007).

DOI: $10.1039 / \mathrm{b} 615954 \mathrm{k}$

[3] Behl M., Lendlein A.: Shape-memory polymers. Materials Today, 10, 20-28 (2007).

DOI: $10.1016 / \mathrm{S} 1369-7021(07) 70047-0$

[4] Behl M., Lendlein A.: Actively moving polymers. Soft Matter, 3, 58-67 (2007).

DOI: $10.1039 / \mathrm{b} 610611 \mathrm{k}$
[5] Rousseau I. A.: Challenges of shape memory polymers: A review of the progress toward overcoming SMP's limitations. Polymer Engineering and Science, 48, 2075-2089 (2008). DOI: $10.1002 /$ pen. 21213

[6] Mather P. T., Luo X., Rousseau I. A.: Shape memory polymer research. Annual Review of Materials Research, 39, 445-471 (2009).

DOI: 10.1146/annurev-matsci-082908-145419

[7] Leng J., Lu H., Liu J., Huang W. M., Du S.: Shapememory polymers - A class of novel smart materials. MRS Bulletin, 34, 848-855 (2009).

DOI: $10.1557 / \mathrm{mrs} 2009.235$

[8] Jiang H-Y., Schmidt A. M.: The structural variety of shape-memory polymers. in 'Shape memory polymers and multifunctional composites’ (eds.: Leng J., Du S.) CRC Press, Boca Raton, 27-63 (2010).

[9] Bellin I., Kelch S., Langer R., Lendlein A.: Polymeric triple-shape materials. Proceedings of the National Academy of Sciences of the United States of America, 103, 18043-18047 (2006).

DOI: $10.1073 /$ pnas.0608586103

[10] Behl M., Bellin I., Kelch S., Wagermaier W., Lendlein A.: One-step process for creating triple-shape capability of AB polymer networks. Advanced Functional Materials, 19, 102-108 (2009). DOI: $10.1002 / \mathrm{adfm} .200800850$

[11] Luo X., Mather P. T.: Triple-shape polymeric composites (TSPCs). Advanced Functional Materials, 20, 2649-2656 (2010).

DOI: $10.1002 / \mathrm{adfm} .201000052$

[12] Kolesov I. S., Radusch H-J.: Multiple shape-memory behavior and thermal-mechanical properties of peroxide cross-linked blends of linear and short-chain branched polyethylenes. Express Polymer Letters, 2, 461-473 (2008).

DOI: $10.3144 /$ expresspolymlett.2008.56

[13] Radusch H-J., Kolesov I. S., Gohs U., Heinrich G.: Multiple shape-memory behavior of polyethylene/ polycyclooctene blends cross-linked by electron irradiation. Macromolecular Materials and Engineering, 297, 1225-1234 (2012).

DOI: $10.1002 /$ mame.201200204

[14] Cuevas J. M., Rubio R., Germán L., Laza J. M., Vilas J. L., Rodrigues M., León L. M.: Triple-shape memory effect of covalently crosslinked polyalkenamer based semicrystalline polymer blends. Soft Matter, 8, 49284935 (2012).

DOI: $10.1039 / \mathrm{c} 2 \mathrm{sm} 07481 \mathrm{~h}$

[15] Li F., Chen Y., Zhu W., Zhang X., Xu M.: Shape memory effect of polyethylene/nylon 6 graft copolymers. Polymer, 39, 6929-6934 (1998).

DOI: $10.1016 / \mathrm{S} 0032-3861(98) 00099-8$

[16] Xie T.: Tunable polymer multi-shape memory effect. Nature, 464, 267-270 (2010).

DOI: $10.1038 /$ nature 08863 
[17] Zhao J., Chen M., Wang X., Zhao X. Wang Z., Dang Z-M., Ma L., Hu G-H., Chen F.: Triple shape memory effects of cross-linked polyethylene/polypropylene blends with cocontinuous architecture. Applied Materials and Interfaces, 5, 5550-5556 (2013). DOI: $10.1021 / \mathrm{am} 400769 \mathrm{~J}$

[18] Bai Y., Zhang X., Wang Q., Wang T.: A tough shape memory polymer with triple-shape memory and twoway shape memory properties. Journal of Materials Chemistry A, 2, 4771-4778 (2014). DOI: $10.1039 / \mathrm{c} 3$ ta $15117 \mathrm{~d}$

[19] Madbouly S. A., Lendlein A.: Degradable polyurethane/ soy protein shape-memory polymer blends prepared via environmentally-friendly aqueous dispersions. Macromolecular Materials and Engineering, 297, 1213 1224 (2012).

DOI: $10.1002 /$ mame.201200341

[20] Karger-Kocsis J., Kéki S.: Biodegradable polyesterbased shape memory polymers: Concepts of (supra) molecular architecturing. Express Polymer Letters, 8, 397-412 (2014).

DOI: $10.3144 /$ expresspolymlett.2014.44

[21] Ratna D., Karger-Kocsis J.: Recent advances in shape memory polymers and composites: A review. Journal of Materials Science, 43, 254-269 (2008).

DOI: $10.1007 / \mathrm{s} 10853-007-2176-7$

[22] Chung T., Romo-Uribe A., Mather P. T.: Two-way reversible shape memory in a semicrystalline network. Macromolecules, 41, 87-96 (2008).

DOI: $10.1021 / \mathrm{ma} 071517 \mathrm{z}$

[23] Pandini S., Passera S., Messori M., Paderni K., Toselli M., Gianoncelli A., Bontempi E., Riccò T.: Two-way reversible shape memory behaviour of crosslinked poly(E-caprolactone). Polymer, 53, 1915-1924 (2012). DOI: $10.1016 /$ j.polymer.2012.02.053

[24] Pandini S., Baldi F., Paderni K., Messori M., Toselli M., Pilati F., Gianoncelli A., Brisotto M., Bontempi E., Riccò T.: One-way and two-way shape memory behaviour of semi-crystalline networks based on sol-gel cross-linked poly( $\varepsilon$-caprolactone). Polymer, 54, 42534265 (2013).

DOI: $10.1016 /$ j.polymer.2013.06.016

[25] Kolesov I. S., Kratz K., Lendlein A., Radusch H-J.: Kinetics and dynamics of thermally-induced shapememory behavior of crosslinked short-chain branched polyethylenes. Polymer, 50, 5490-5498 (2009). DOI: $10.1016 /$ j.polymer.2009.09.062

[26] Kolesov I. S., Radusch H-J.: Investigation on the performances of the peroxidic initiated network in shapememory materials on the basis of ethylene-1-octenecopolymers and their blends with HDPE by means of deformation behavior and stress relaxation. in 'Proceeding of the Polymer Processing Society $24^{\text {th }}$ Annual Meeting (PPS-24). Salerno, Italy' 1-6, (2008).
[27] Zotzmann J., Behl M., Hofmann D., Lendlein A.: Reversible triple-shape effect of polymer networks containing polypentadecalactone- and poly( $\varepsilon$-caprolactone)-segments. Advanced Materials, 22, 34243429 (2010). DOI: $10.1002 / \mathrm{adma} .200904202$

[28] Basit A., L'Hostis G., Pac M. J., Durand B.: Thermally activated composite with two-way and multi-shape memory effects. Materials, 6, 4031-4045 (2013). DOI: $10.3390 / \mathrm{ma} 6094031$

[29] Imai S.: Operating methods for two-way behavior shape memory polymer actuators without using external stress. IEEJ Transactions on Electrical and Electronic Engineering, 9, 90-96 (2014).

DOI: $10.1002 /$ tee. 21940

[30] Westbrook K. K., Mather P. T., Parakh V., Dunn M. L., Ge Q., Lee B. M., Qi H. J.: Two-way reversible shape memory effects in a free-standing polymer composite. Smart Materials and Structures, 20, 065010/1065010/9 (2011).

DOI: $10.1088 / 0964-1726 / 20 / 6 / 065010$

[31] Behl M., Kratz K., Noechel U., Sauter T., Lendlein A.: Temperature-memory polymer actuators. Proceedings of the National Academy of Sciences of the United States of America, 110, 12555-12559 (2013).

DOI: $10.1073 /$ pnas. 1301895110

[32] Behl M., Kratz K., Zotzmann J., Nöchel U., Lendlein A.: Reversible bidirectional shape-memory polymers. Advanced Materials, 25, 4466-4469 (2013). DOI: $10.1002 / \mathrm{adma} .201300880$

[33] Wu Y., Hu J., Han J., Zhu Y., Huang H., Li J., Tang B.: Two-way shape memory polymer with 'switch-spring' composition by interpenetrating polymer network. Journal of Materials Chemistry A, 2, 18816-18822 (2014).

DOI: $10.1039 / \mathrm{c} 4 \mathrm{ta} 03640 \mathrm{a}$

[34] Tobushi H., Okumura K., Hayashi S., Ito N.: Thermomechanical constitutive model of shape memory polymer. Mechanics of Materials, 33, 545-554 (2001). DOI: 10.1016/S0167-6636(01)00075-8

[35] Barot G., Rao I. J.: Constitutive modeling of the mechanics associated with crystallizable shape memory polymers. Zeitschrift für angewandte Mathematik und Physik ZAMP, 57, 652-681 (2006). DOI: $10.1007 / \mathrm{s} 00033-005-0009-6$

[36] Barot G., Rao I. J., Rajagopal K. R.: A thermodynamic framework for the modeling of crystallizable shape memory polymers. International Journal of Engineering Science, 46, 325-351 (2008). DOI: $10.1016 /$ j.ijengsci.2007.11.008

[37] Qi H. J., Nguyen T. D., Castro F., Yakacki C. M., Shandas R.: Finite deformation thermo-mechanical behavior of thermally induced shape memory polymers. Journal of the Mechanics and Physics of Solids, 56, 1730-1751 (2008). DOI: $10.1016 /$ j.jmps.2007.12.002 
[38] Husson J. M., Dubois F., Sauvat N.: A finite element model for shape memory behavior. Mechanics of TimeDependent Materials, 15, 213-237 (2011).

DOI: $10.1007 / \mathrm{s} 11043-011-9134-0$

[39] Böl M., Reese S.: Micromechanical modelling of shape memory polymers. Advances in Science and Technology, 54, 137-142 (2008).

DOI: $10.4028 /$ www.scientific.net/AST.54.137

[40] Sinha R. P., Jarali C. S., Raja S.: Modelling the thermomechanical behaviour of shape memory polymer materials. Indian Journal of Engineering and Materials Sciences, 18, 15-23 (2011).

[41] Liu Y., Gall K., Dunn M. L., Greenberg A. R., Diani J.: Thermomechanics of shape memory polymers: Uniaxial experiments and constitutive modeling. International Journal of Plasticity, 22, 279-313 (2006). DOI: $10.1016 /$ j.ijplas.2005.03.004

[42] Ge Q., Yu K., Ding Y., Qi H. J.: Prediction of temperature-dependent free recovery behaviors of amorphous shape memory polymers. Soft Matter, 8, 11098-11105 (2012). DOI: $10.1039 / \mathrm{C} 2 \mathrm{SM} 26249 \mathrm{E}$

[43] Khonakdar H. A., Jafari S. H., Rasouli S., Morshedian J., Abedini H.: Investigation and modeling of temperature dependence recovery behavior of shape-memory crosslinked polyethylene. Macromolecular Theory and Simulations, 16, 43-52 (2007). DOI: $10.1002 /$ mats.200600041

[44] Wang Z. D., Li D. F., Xiong Z. Y., Chang R. N.: Modeling thermomechanical behaviors of shape memory polymer. Journal of Applied Polymer Science, 113, 651-656 (2009).

DOI: 10.1002/app.29656

[45] Heuchel M., Cui J., Kratz K., Kosmella H., Lendlein A.: Relaxation based modeling of tunable shape recovery kinetics observed under isothermal conditions for amorphous shape-memory polymers. Polymer, 51, 6212-6218 (2010).

DOI: $10.1016 /$ j.polymer.2010.10.051

[46] Westbrook K. K., Parakh V., Chung T., Mather P. T., Wan L. C., Dunn M. L., Qi H. J.: Constitutive modeling of shape memory effects in semicrystalline polymers with stretch induced crystallization. Journal of Engineering Materials and Technology, 132, 041010/1041010/9 (2010).

DOI: $10.1115 / 1.4001964$
[47] Kolesov I. S., Radusch H-J.: Deformation behavior of random ethylene-1-octene-copolymers under longterm loading. in 'Proceeding of the Polymer Processing Society $21^{\text {st }}$ Annual Meeting (PPS-21). Leipzig, Germany' 1-9 (2005).

[48] Kolesov I., Dolynchuk O., Borreck S., Radusch H-J.: Morphology-controlled multiple one- and two-way shape-memory behavior of cross-linked polyethylene/ poly( $\varepsilon$-caprolactone) blends. Polymers for Advanced Technologies, 25, 1315-1322 (2014). DOI: $10.1002 /$ pat.3338

[49] Tadaki T.: Cu-based shape memory alloys. in 'Shape memory materials' (eds.: Otsuka K., Wayman C. M.) Cambridge University Press, Cambridge, 109-116 (1998).

[50] Chen H. Y.: Carbon-13 NMR-spectra of polyalkenamers. in 'Applications of polymer spectroscopy' (ed: Brame E. G.) Academic Press, New York, 7-17 (1978).

[51] Kolesov I., Dolynchuk O., Radusch H. J.: Modeling of shape-memory recovery in crosslinked semicrystalline polymers. Advances in Science and Technology, 77, 319-324 (2012).

DOI: 10.4028/www.scientific.net/AST.77.319

[52] Kolesov I., Dolynchuk O., Radusch H-J.: Theoretical description of unconstrained thermally induced shapememory recovery in crosslinked polyethylenes. Journal of Polymer Science Part B: Polymer Physics, 52, 815-822 (2014). DOI: $10.1002 /$ polb.23491

[53] Krausz A. S., Eyring H.: Deformation kinetics. Wiley, New York (1975).

[54] Ziabicki A.: Theoretical analysis of oriented and non isothermal crystallization. Colloid and Polymer Science, 252, 207-221 (1974).

DOI: $10.1007 / \mathrm{BF} 01638101$

[55] Dolynchuk O., Kolesov I., Radusch H-J.: Thermodynamic description and modeling of two-way shapememory effect in crosslinked semicrystalline polymers. Polymers for Advanced Technologies, 25, 1307-1314 (2014).

DOI: $10.1002 /$ pat.3335

[56] Gaylord R. J.: A theory of the stress-induced crystallization of crosslinked polymeric networks. Journal of Polymer Science: Polymer Physics Edition, 14, 18271837 (1976). DOI: $10.1002 /$ pol.1976.180141008 